\title{
Disclosing the Binding Medium Effects and the Pigment Solubility in the (Photo)reduction Process of Chrome Yellows ( $\mathrm{PbCrO}_{4} /$ $\left.\mathrm{PbCr}_{1-x} \mathrm{~S}_{x} \mathrm{O}_{4}\right)$
}

Letizia Monico, ${ }^{*}, \dagger, \ddagger, \S \odot$ Lorenzo Sorace, ${ }^{\| \bullet}$ Marine Cotte, ${ }^{\perp, \#}$ Wout de Nolf, ${ }^{\perp}$ Koen Janssens, Aldo Romani, ${ }^{\dagger,}$ and Costanza Miliani ${ }^{+} \dagger$

${ }^{\dagger}$ SMAArt Centre and Department of Chemistry, Biology and Biotechnology, University of Perugia, via Elce di Sotto 8, 06123 Perugia, Italy

${ }^{\ddagger}$ CNR-Institute of Molecular Science and Technologies (CNR-ISTM), via Elce di Sotto 8, 06123 Perugia, Italy

${ }^{\S}$ Department of Chemistry, AXES Research Group, University of Antwerp, Groenenborgerlaan 171, 2020 Antwerp, Belgium

"Department of Chemistry "Ugo Schiff” and INSTM RU, University of Florence, via della Lastruccia 3-13, 50019 Sesto Fiorentino, Italy

${ }^{\perp}$ European Synchrotron Radiation Facility (ESRF), BP 220, 38043 Grenoble Cedex, France

\#Laboratoire d'archéologie moléculaire et structurale (LAMS), Sorbonne Université, CNRS, UMR 8220, 75005 Paris, France

Supporting Information

ABSTRACT: The darkening due to chemical alteration of chrome yellows $\left(\mathrm{PbCrO}_{4} / \mathrm{PbCr}_{1-x} \mathrm{~S}_{x} \mathrm{O}_{4}\right)$ is a phenomenon threatening a large number of 19th-20th century paintings, including the Amsterdam Sunflowers by Vincent van Gogh. Our earlier studies have proven that the alteration is due to a $\mathrm{Cr}(\mathrm{VI}) \rightarrow \mathrm{Cr}(\mathrm{III})$ reduction with $\mathrm{Cr}(\mathrm{V})$-species that are formed as long-lived intermediates and that $\mathrm{PbCr}_{1-x} \mathrm{~S}_{x} \mathrm{O}_{4}(0<x \leq 0.8)$ types undergo reduction more readily than monoclinic, $\mathrm{S}$-free, $\mathrm{PbCrO}_{4}$. In this context, there is still lack of knowledge about the effects of the chemical properties of the binding medium (i.e., chemical composition and drying process) and the solubility of chrome yellows on the overall reduction pathways. Here, we study a series of naturally and photochemically aged mock-up paints prepared by mixing chrome yellow powders $\left(\mathrm{PbCrO}_{4} / \mathrm{PbCr}_{0.2} \mathrm{~S}_{0.8} \mathrm{O}_{4}\right)$ with either linseed oil or a water-based acrylic emulsion as the binding medium. Equivalent paints made

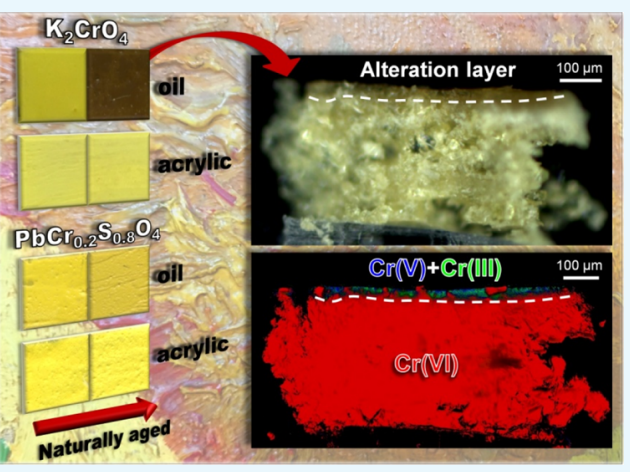
up of the highly soluble $\mathrm{K}_{2} \mathrm{CrO}_{4}$ were also investigated and used as benchmarks to provide a more in-depth understanding of the influence of the solubility on the chromate reduction pathways in the two different binders. A combination of synchrotron radiation-based Cr K-edge X-ray absorption near edge structure (XANES), electron paramagnetic resonance (EPR), and UVVisible spectroscopy measurements shows that: (1) the $\mathrm{Cr}(\mathrm{VI})$ reduction results from the interaction between the pigment and the binder; (2) the process is more significant in oil, giving rise to $\mathrm{Cr}(\mathrm{V})$ - and $\mathrm{Cr}(\mathrm{III})$-species as well as oxidized organic compounds; (3) the lightfastness of the chrome yellow pigment is enhanced in the acrylic binder; and (4) the tendency toward chromium reduction increases with increasing solubility of the pigment. Based on our findings, we propose a scheme for the mechanism of the (photo)reduction process of chrome yellows in the oil and acrylic binder. Overall, our results provide new insights into the factors driving the degradation of lead chromate-based paints in artworks and contribute to the development of strategies for preserving them over time.

\section{INTRODUCTION}

The term chrome yellows (hereafter named "CYs") denotes a class of 19th-20th century yellow-orange/lemon yellow artists' pigments, which comprises different chemical varieties: lead chromate $\left(\mathrm{PbCrO}_{4}\right)$ and the co-precipitates of lead chromate and lead sulfate $\left(\mathrm{PbCr}_{1-x} \mathrm{~S}_{x} \mathrm{O}_{4}\right.$, with $\left.0<x \leq 0.8\right)$. The two solid solution end members $\mathrm{PbCrO}_{4}$ and $\mathrm{PbSO}_{4}$ belong to the monoclinic and orthorhombic crystal systems, respectively; when $\mathrm{x}$ increases beyond $\sim 0.4-0.5$, a change from monoclinic to orthorhombic structure is observed in $\mathrm{PbCr}_{1-x} \mathrm{~S}_{x} \mathrm{O}_{4}{ }^{1-4}$
CYs often occur in paintings of Impressionist and PostImpressionist artists, such as Claude Monet, ${ }^{5-7}$ Paul Gauguin, $3,8,9$ Vincent van Gogh, ${ }^{3,4,10,11}$ and Georges Seurat. $^{12,13}$ Unfortunately, some yellow paints of a number of artworks by these masters have darkened due to chemical alteration of CYs. ${ }^{11,12}$ It has been reported that not only the exposure to specific environmental conditions (in terms of

Received: December 30, 2018

Accepted: March 26, 2019

Published: April 10, 2019 
light and humidity), ${ }^{14-17}$ but also the intrinsic properties of $\mathrm{CY}$ (i.e., $\mathrm{Cr} / \mathrm{S}$ stoichiometry and crystalline structure) ${ }^{18}$ as well as the presence of additives/fillers related to the manufacturing process of the pigment itself $^{19-21}$ are possible factors influencing the darkening of the paint.

A multitechnique study of microsamples taken from Van Gogh's paintings, ${ }^{11,22-24}$ historical paint tubes, and mock-up paints ${ }^{14-18}$ permitted us to assess the stability of different varieties of CYs in the oil binder. We demonstrated that the darkening is due to a $\mathrm{Cr}(\mathrm{VI}) \rightarrow \mathrm{Cr}(\mathrm{III})$ photoreduction with paramagnetic $\mathrm{Cr}(\mathrm{V})$-intermediates that are formed through the interaction of the pigment with the oil. ${ }^{14,15}$ Moreover, we found that monoclinic and/or orthorhombic $\mathrm{PbCr}_{1-x} \mathrm{~S}_{x} \mathrm{O}_{4}(0<$ $x \leq 0.8)$ varieties discolor more readily than monoclinic $\mathrm{S}$-free $\mathrm{PbCrO}_{4}$, possibly as a consequence of the different solubility of each pigment in the binding medium. ${ }^{18}$ In this regard, we know that the solubility in water of lead chromates increases with increasing sulfate in the $\mathrm{PbCr}_{1-x} \mathrm{~S}_{x} \mathrm{O}_{4}$ solid solutions and when the compound is present in the orthorhombic crystalline structure. $^{2,3}$

More recently, computational studies employing density functional theory methods have been performed with the aim to explain any possible relationships between the structural and electronic properties of the CY pigment and their crystalline structure and sulfate content. ${ }^{25,26}$ From a purely electronic point of view, the findings of these studies are in contradiction with the experimental results. The band gap increases and the conduction band shifts up with increasing sulfate content and with changing of the crystalline structure in CY; thus, a lower photoreactivity should be expected for the sulfate-richest forms of the pigment. In a follow-up study, Rahemi et al. ${ }^{27}$ have explained the experimental results by exploiting a combination of first-principles calculations and photoelectrochemical measurements of CY pigment powders. It has been concluded that the higher content of reduced $\mathrm{Cr}$ in sulfate-rich phases is related to the p-type semi-conductor properties of CYs as well as to their absorption and reflection coefficients, which change as a result of the sulfate doping in such a way that the generation of electron-hole pairs under illumination relative to the total $\mathrm{Cr}$ content increases.

However, in this context, a systematic evaluation of (i) the effects of different organic binding media on the degradation pathways of CYs and (ii) any possible correlation between the CY solubility and its (photo)chemical reactivity in the organic matrix has not yet been done. Gaining more insights into both these aspects is important for adding new knowledge on the effect of sulfate substitution on the chromate-reduction process and thus on the overall degradation mechanism of $\mathrm{CY}$ pigments.

To this aim, in this work we investigated a series of mock-up paints prepared by employing two $\mathrm{CY}$ types of different solubility (s) in water (at ca. $20{ }^{\circ} \mathrm{C}$ ): (a) monoclinic $\mathrm{PbCrO}_{4}$ $\left(s_{\mathrm{PbCrO}_{4}}=5 \times 10^{-7} \mathrm{~mol} / \mathrm{L}\right)$ and (b) mainly orthorhombic $\mathrm{PbCr}_{0.2} \mathrm{~S}_{0.8} \mathrm{O}_{4}$ solid solution (more soluble; $5 \times 10^{-7} \mathrm{~mol} / \mathrm{L}<$ $\left.s_{\mathrm{PbCr}_{0.2} \mathrm{~S}_{0.8} \mathrm{O}_{4}}<2 \times 10^{-4} \mathrm{~mol} / \mathrm{L}\right){ }^{2,3}$ Additional paints made up of the highly water-soluble orthorhombic $\mathrm{K}_{2} \mathrm{CrO}_{4}\left(s_{\mathrm{K}_{2} \mathrm{CrO}_{4}}=3.56\right.$ $\mathrm{mol} / \mathrm{L}$ ) were also studied and used as benchmarks to provide a more in-depth understanding of the effects of the compound's solubility on the chromate reduction pathways. Watersolubility values are here qualitatively considered, since precise values in the two different binders are not available. Previous studies report that the solubility of different chromate-based compounds, including lead chromate, is comparable or slightly enhanced in various biological media and aminopolycarboxylic acids with respect to that in water. ${ }^{28,29}$

Regarding the binding media, either linseed oil or a waterbased acrylic emulsion was chosen. Even though the former has been mainly employed with CYs by the 19th-20th century artists, ${ }^{7,11,13}$ the two binders were selected due to their different chemical composition and drying process. Oil paints dry as a consequence of an autoxidation process (i.e., a free radical chain reaction), that involves cross-linking reactions between the triacylglycerols. ${ }^{30}$ On the other hand, during drying of acrylic emulsions, water evaporation brings the polymer particles closer, which then coalesce forming a continuous film. ${ }^{31,32}$

A multitechnique approach based on the combination of diffuse reflectance UV-Visible spectroscopy with metalspeciation methods, namely X-band ( $\nu$ ca. $9.5 \mathrm{GHz}$ ) EPR spectroscopy and synchrotron radiation (SR)-based Cr K-edge XANES spectroscopy (in point analysis and full-filed imaging mode) permitted us to obtain bulk and stratigraphic information associated to the optical and $\mathrm{Cr}$ speciation changes induced by the natural and photochemical aging of paint films.

\section{EXPERIMENTAL SECTION}

2.1. Preparation of Mock-Up Paints and Photochemical Aging Protocol. Mock-up paints were prepared on polycarbonate slices by employing powders of different solubility in water: monoclinic $\mathrm{PbCrO}_{4}$ and mainly orthorhombic $\mathrm{PbCr}_{0.2} \mathrm{~S}_{0.8} \mathrm{O}_{4}$ (both synthesized in our laboratory) as well as commercial orthorhombic $\mathrm{K}_{2} \mathrm{CrO}_{4}$ (Sigma-Aldrich). Further information about the synthesis, crystalline structure, and molecular properties of monoclinic $\mathrm{PbCrO}_{4}$ and mainly orthorhombic $\mathrm{PbCr}_{0.2} \mathrm{~S}_{0.8} \mathrm{O}_{4}$ (henceforward denoted " $\mathrm{CY}_{0}$ " and " $\mathrm{CY}_{0.8}$ ", respectively) is reported in previous studies.

The chromate-based powders were used in mixture with either one of the following organic binding media in a 4:1 weight ratio: linseed oil (Zecchi) or Primal B60-A (C.T.S.), a water-based acrylic emulsion ( $47 \%$ solids content) containing a copolymer of ethyl acrylate and methyl methacrylate (hereafter called "acrylic").

All paints were left to dry in the dark at temperatures of 25$35{ }^{\circ} \mathrm{C}$ and $35-45 \%$ relative humidity ( $\mathrm{RH}$ ) (i.e., measured indoor temperature and humidity level) and then analyzed at different curing stages, starting from 15 days (hereafter denoted "touch-dry") up to 20 months. The samples measured after 15 days are henceforth called "naturally aged".

Photochemical aging of 3 months naturally aged CY paints was carried out at $\sim 35-45 \% \mathrm{RH}$ (measured indoor humidity level) by means of UVA-Visible light $(\lambda \geq 300 \mathrm{~nm})$ emitted by a UV-filtered $300 \mathrm{~W}$ Cermax xenon lamp (see ref 14 for the corresponding emission spectral profile). The measured illuminance and temperature at the samples position were $1.6 \times 10^{5}$ lux (irradiance: $3.0 \times 10^{5} \mu \mathrm{W} / \mathrm{cm}^{2}$ ) and $25-30{ }^{\circ} \mathrm{C}$, respectively. Paints were irradiated for $137 \mathrm{~h}$, to achieve total luminous exposure values of $2.2 \times 10^{7} \mathrm{lux} \cdot \mathrm{h}$ (total radiant exposure: $\left.4.1 \times 10^{7} \mu \mathrm{W} / \mathrm{cm}^{2} \cdot \mathrm{h}\right)$.

2.2. Analytical Methods. 2.2.1. UV-Visible Spectroscopy. A JASCO V-570 spectrophotometer was employed for recording diffuse reflectance UV-Visible spectra from the paint surface of all mock-ups. Spectral data were acquired in the $200-850 \mathrm{~nm}$ range with a $5 \mathrm{~nm}$ spectral resolution. The software interfaced with the instrumentation permitted to 

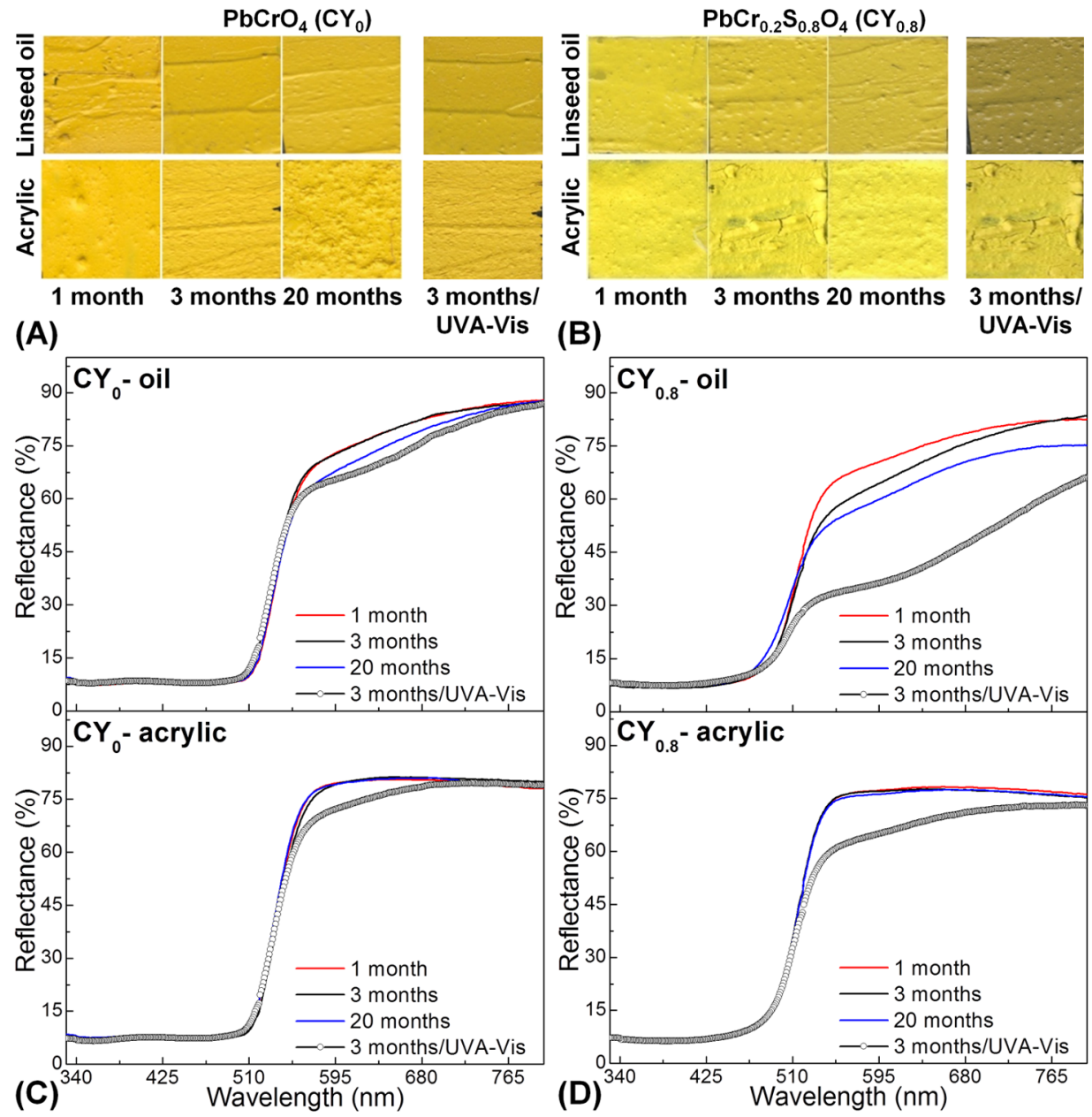

Figure 1. Photographs of (A) $\mathrm{PbCrO}_{4}\left(\mathrm{CY}_{0}\right)$ and (B) $\mathrm{PbCr}_{0.2} \mathrm{~S}_{0.8} \mathrm{O}_{4}\left(\mathrm{CY}_{0.8}\right)$ mock-up paints obtained using either (top) linseed oil or (bottom) acrylic as binding medium and aged either naturally for 1, 3, and 20 months (left) or by UVA-Visible light (right). (C,D) Diffuse reflectance UVVisible spectra acquired from the paints shown in $(\mathrm{A}, \mathrm{B})$ [see Table 1 for the variation of colorimetric coordinates $L^{*}, a^{*}, b^{*}$ and the total color change $\left(\Delta E^{*}\right)$ versus natural aging time and after photochemical aging].

perform the conversion of the spectra into CIE $L^{*} a^{*} b^{*}$ colorimetric coordinates under the standard illuminant D65 and $10^{\circ}$ angle observer. Total color differences were calculated according to the CIE 1976 formula, $\Delta E^{*}=\left(\Delta L^{* 2}+\Delta a^{* 2}+\right.$ $\left.\Delta b^{* 2}\right)^{1 / 2}$.

2.2.2. EPR Spectroscopy. X-band ( $\nu$ ca. $9.5 \mathrm{GHz}$ ) EPR spectra of CYs and $\mathrm{K}_{2} \mathrm{CrO}_{4}$ paints were recorded at room temperature using a Bruker E500 continuous-wave spectrometer. Exact frequency values along with other relevant experimental parameters are reported in captions of Figures 2,4 and 6.

For each analyzed paint, $g$-values of each signal $\left(g_{\text {signal }}\right)$ were obtained by the corresponding resonant field $\left(B_{\text {res }}\right)$ after calibration against the resonance field of the radical $\alpha, \gamma$ bisdiphenylene- $\beta$-phenylallyl (BDPA; $\left.g_{\mathrm{BDPA}}=2.00264\right)$, used as standard according to the following relation

$$
g_{\text {signal }}=2.00264 \times B_{\text {res }}(\mathrm{BDPA}) / B_{\text {res }}(\text { signal })
$$

This was measured for the different setups as a polystyrene dispersion.

Spectra were recorded from a tube containing a weighed amount of sample between 5 and $15 \mathrm{mg}$. For the photochemically aged $\mathrm{CY}_{0.8}$ samples and the naturally aged $\mathrm{K}_{2} \mathrm{CrO}_{4}$ paints, data were obtained from a portion of the material that was selectively sampled from the surface (less than $100-150 \mu \mathrm{m}$ in depth).

The intensity of each spectrum was normalized to the number of moles of chromium contained in the corresponding sample. The ratio between the signals attributed to $\mathrm{Cr}(\mathrm{III})$ and $\mathrm{Cr}(\mathrm{V})$-species was obtained by double integration of the Lorentzian [for $\mathrm{Cr}(\mathrm{III})$ ] and Gaussian [for $\mathrm{Cr}(\mathrm{V})$ ] curves, which yielded the best description of the experimental spectra.

2.2.3. SR-Based Cr K-Edge XANES Spectroscopy. $\mathrm{CY}_{0.8}$ and $\mathrm{K}_{2} \mathrm{CrO}_{4}$ mock-up paints were analyzed as thin sections (thickness of $5-10 \mu \mathrm{m}$ ) at the X-ray microscope beamline ID21 of the European Synchrotron Radiation Facility (ESRF, Grenoble, FR). ${ }^{33}$ Here, a highly monochromatic primary beam (with $\Delta E / E=10^{-4}$ ) was obtained with a $\operatorname{Si}(220)$ fixed-exit double-crystal monochromator.

$\mathrm{CY}_{0.8}$ paints were studied at the scanning X-ray microspectroscopy end-station.

At the exit of the monochromator, the incident beam was focused with Kirkpatrick-Baez mirrors to a spot size of about $0.9 \times 0.4 \mu \mathrm{m}^{2}(h \times \nu)$. Around the Cr K-edge energy range (5.96-6.09 keV), the stability of the beam was within 0.6 and $0.2 \mu \mathrm{m}$ in the vertical and horizontal directions, respectively. $\mu$-XANES spectra in XRF mode were recorded under vacuum by scanning the primary energy across the Cr K-edge with energy increments of $0.2 \mathrm{eV}$ and using a silicon drift detector 
Table 1. Variation of Colorimetric Coordinates $L^{*}, a^{*}, b^{*}$ and Total Color Change Values $\left(\Delta E^{*}\right)$ of Naturally Aged and Photochemically Aged $\mathrm{CY}_{0}$ and $\mathrm{CY}_{0.8}$ Oil and Acrylic Paints

\begin{tabular}{|c|c|c|c|c|c|c|}
\hline aging process & sample $^{a}$ & aging time & $\Delta L^{*}$ & $\Delta a^{*}$ & $\Delta b^{*}$ & $\Delta E^{*}$ \\
\hline \multirow[t]{8}{*}{ natural aging } & \multirow[t]{2}{*}{$\mathrm{CY}_{0}-\mathrm{oil}$} & 3 months & 0.9 & -2.6 & -0.6 & 2.8 \\
\hline & & 20 months & -1.5 & -1.8 & -3.2 & 4.0 \\
\hline & \multirow[t]{2}{*}{$\mathrm{CY}_{0}$-acrylic } & 3 months & -1.0 & 0.5 & -0.7 & 1.3 \\
\hline & & 20 months & 0.2 & -0.7 & -0.4 & 0.8 \\
\hline & \multirow[t]{2}{*}{$\mathrm{CY}_{0.8}-$ oil } & 3 months & -3.0 & 0.9 & -5.2 & 6.1 \\
\hline & & 20 months & -4.2 & -2.2 & -10.0 & 11.1 \\
\hline & \multirow[t]{2}{*}{$\mathrm{CY}_{0.8}$-acrylic } & 3 months & 0.0 & -0.4 & 0.1 & 0.4 \\
\hline & & 20 months & -0.3 & -0.2 & -0.8 & 0.9 \\
\hline \multirow[t]{4}{*}{ photochemical aging (UVA-Vis light) ${ }^{b}$} & $\mathrm{CY}_{0}-\mathrm{oil}$ & $137 \mathrm{~h}$ & -2.6 & -3.0 & -4.6 & 6.1 \\
\hline & $\mathrm{CY}_{0}$-acrylic & $137 \mathrm{~h}$ & -2.5 & -1.0 & -4.3 & 5.1 \\
\hline & $\mathrm{CY}_{0.8}-$ oil & $137 \mathrm{~h}$ & -17.1 & -3.6 & -31.0 & 35.6 \\
\hline & $\mathrm{CY}_{0.8}$-acrylic & $137 \mathrm{~h}$ & -5.5 & 0.9 & -9.7 & 11.2 \\
\hline
\end{tabular}

${ }^{a}$ Photochemical aging experiments were carried out on 3 months naturally aged paints. ${ }^{b}$ Experiments were performed using illuminance and irradiance values of $1.6 \times 10^{5}$ lux and $3.0 \times 10^{5} \mu \mathrm{W} / \mathrm{cm}^{2}$, respectively (see Section 2.1 for further details).

(Xflash 5100, Bruker). A one-dimensional series of $\mu$-XANES spectra was acquired along a line perpendicular to the stratigraphy of each paint, starting from the exposed surface of the sample. The ATHENA software package ${ }^{34}$ was employed for the normalization and for the linear combination fitting (LCF) of the spectra against a library of XANES profiles of Cr-reference powders.

This procedure allowed the relative amount of the $\mathrm{Cr}(\mathrm{VI})$ species (expressed as $\%[\mathrm{Cr}(\mathrm{VI})] /\left[\mathrm{Cr}_{\text {total }}\right]$ ) and of the reduced Cr-compounds as a function of the depth of the paint to be determined quantitatively. We have previously described ${ }^{15}$ that the distinction between different reduced Cr-species [that is, $\mathrm{Cr}(\mathrm{V})$ and $\mathrm{Cr}(\mathrm{III})]$ is challenging by XANES spectroscopy, especially when they are present in mixture and when also $\mathrm{Cr}(\mathrm{VI})$-compounds are present. Thus, their relative abundance is hereafter referred to as "reduced chromium total" (\% $\left.\left[\mathrm{Cr}_{\text {reduced }}\right] /\left[\mathrm{Cr}_{\text {total }}\right]\right)$.

$\mathrm{K}_{2} \mathrm{CrO}_{4}$ paints were investigated at the full-field (FF) endstation. The energy of the incident unfocused X-ray beam (size of $\sim 1.5 \times 1.5 \mu \mathrm{m}^{2}$ ) was tuned over the Cr K-edge and a stack of no. $274 \mathrm{X}$-ray transmission radiographs was recorded with the following variable step sizes: between 1 and $5 \mathrm{eV}$ above the pre-edge peak $(5.9593-5.9837 \mathrm{keV})$ and in the post-edge absorption region $(6.0887-6.0857 \mathrm{keV})$, between 0.2 and 0.5 $\mathrm{eV}$ around the pre-edge peak and the absorption edge (5.9837-6.0487 keV). A $10 \mu \mathrm{m}$ thick $\mathrm{Lu}_{2} \mathrm{SiO}_{5} / \mathrm{Tb}$ scintillator (located downstream the sample and at a distance less than 2 $\mathrm{mm}$ ) was used to convert X-ray transmission images into visible images. A $10 \times$ optical objective was used to magnify each image onto a CMOS camera (PCO edge, Germany), giving a pixel size of about $0.65 \times 0.65 \mu \mathrm{m}^{2}$, a spatial resolution of $\sim 1.5 \mu \mathrm{m}$, and a maximum field of view of about $1.5 \times 1.5$ $\mathrm{mm}^{2}$. The Spectrocrunch library ${ }^{33}$ was employed for performing the dark and flat-field correction as well as the alignment of the stack of images. The TXM-Wizard software package ${ }^{35}$ was used to produce $\mathrm{Cr}$ phase maps that were obtained by describing the XANES spectra at each pixel as a linear combination of a set of XANES spectra of different Crreference compounds. The combination yielding the best fit quality (evaluated on the basis of the $\chi$-square, reduced $\chi$ square and $R$-factor values) was chosen as the most likely set of $\mathrm{Cr}$ compounds present at that location.

It has been reported that the exposure to SR X-ray sources may induce chemical changes of lead chromate-based compounds, ${ }^{36}$ and thus preliminary tests have been performed in order to determine the safest conditions of analysis of each paint sample.

\section{RESULTS AND DISCUSSION}

3.1. Effects of the Binding Medium. Our previous investigations highlighted that the reduction of chromate to $\mathrm{Cr}(\mathrm{V})$-compounds in $\mathrm{CY}$ oil paints already takes place spontaneously at normal room temperature and $\mathrm{RH}^{14,15}$ These findings suggest that the reaction may involve an electron-transfer from the lipidic matrix to $\mathrm{Cr}(\mathrm{VI})$, giving rise to $\mathrm{Cr}(\mathrm{V})$ and an oxidized from the oil binder.

Inspired by such hypothesis, we started exploring the chromate reduction process in relation to the chemical nature and drying process of the oil and acrylic binders (Section 3.1.1). As a second step, we have evaluated what the influence is of the two binding media on the lightfastness of the CY pigments (Section 3.1.2).

3.1.1. Naturally Aged CY Mock-Up Paints. Figure 1A,B (left side) shows photographs of the mock-up paints made by mixing $\mathrm{CY}_{0}$ or $\mathrm{CY}_{0.8}$ with either linseed oil or acrylic binder after 1, 3, and 20 months of natural aging. With increasing aging time, oil mock-ups (hereafter referred to as " $\mathrm{CY}_{0}$-oil" and "CY 0. -oil") clearly exhibit a more significant darkening compared to the equivalent acrylic paints (called " $\mathrm{CY}_{0^{-}}$ acrylic" and " $\mathrm{CY}_{0.8}$-acrylic"). As shown in Table 1 , colorimetric measurements of the paint surface confirm the visual observation, revealing that the total color change $\left(\Delta E^{*}\right)$ is negligible $(\leq 1.3)$ for $\mathrm{CY}_{0}$-acrylic and $\mathrm{CY}_{0.8}$-acrylic samples, whereas it becomes appreciable in the equivalent oil mock-ups, achieving values up to about 4 and 11 for the 20 months-aged $\mathrm{CY}_{0}$-oil and $\mathrm{CY}_{0.8}$-oil paints, respectively. The corresponding diffuse reflectance UV-Vis spectra (Figure 1C,D: solid lines) show a decrease in the $510-765 \mathrm{~nm}$ range, leading to variations in yellowness $\left(\Delta b^{*}\right.$ : from ca. -3 to -10$)$, which corresponds to the major contribution to $\Delta E^{*}$, whereas changes of lightness ( $\Delta L^{*}$ : from -1.5 to $\left.\sim-4\right)$ and redness $\left(\Delta a^{*}: \sim-2\right)$ are smaller (Table 1$)$. These results are ascribable to the formation of reduced $\mathrm{Cr}$-compounds, ${ }^{37-39}$ even though the yellowing of the organic binding medium may have slightly contributed to the total color change too. ${ }^{32,40,41}$

To gain insights into $\mathrm{Cr}$ speciation, EPR spectroscopy measurements were performed on the touch dry paints (Figure $2 \mathrm{~A}$ ) as well as the 8 months [Figure $\mathrm{S} 1$ (Supporting 

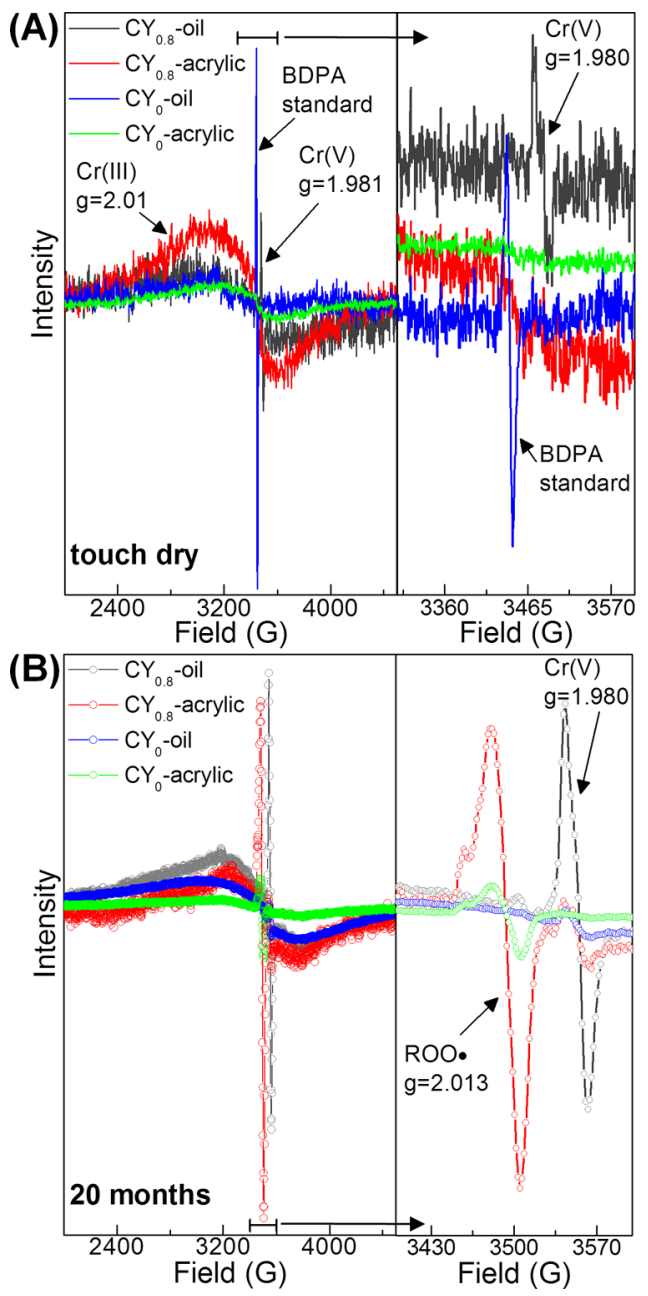

Figure 2. Room-temperature X-band EPR spectra of $\mathrm{CY}_{0} / \mathrm{CY}_{0.8}$ oil (blue and red lines) and acrylic (green and black lines) paints: (A) touch dry samples $(\nu=9.658 \mathrm{GHz}$, microwave power $=6.6 \mathrm{~mW}$, ER4116 Bruker cavity with cryostat) and (B) 20 months naturally aged samples $(\nu=9.847 \mathrm{GHz}$, microwave power $=6.6 \mathrm{~mW}$, SHQ Bruker cavity). The intensity of each spectrum is rescaled by the total number of chromium moles [see Figure S1 (Supporting Information) for the profiles recorded from the 8 months naturally aged paints]. The highest signal to noise ratio in the spectra of naturally aged paints compared to the touch dry ones is due to the increase in the abundance of EPR active Cr-species in the aged samples (see text for further details).
Information)] and 20 months (Figure 2B) naturally aged samples. The comparison among the EPR spectra obtained from the touch dry paints (Figure $2 \mathrm{~A}$ ) shows that a narrow and weakly anisotropic signal at $g=1.980 \pm 0.005$ is present only in the profile of $\mathrm{CY}_{0.8}$-oil paint (dark gray solid line). This spectral feature can be readily attributed to oxo- $\mathrm{Cr}(\mathrm{V})$ complexes. $^{42,43}$ A broad feature centered at $g=2.01 \pm 0.02$, which is consistent with literature-reported EPR spectra of $\mathrm{Cr}$ (III)-carboxylate derivatives, ${ }^{44}$ is evident for all the paints. The signal is more intense for two $\mathrm{CY}_{0.8}$ paints and specifically for the $\mathrm{CY}_{0.8}$-acrylic sample (red solid line).

With increasing natural aging time (from 8 up to 20 months), the spectra of each sample evolve differently depending on both the nature of the binder and the type of lead chromate compound. After 20 months (Figure 2B), the spectrum of the $\mathrm{CY}_{0.8}$-oil sample (dark gray dotted line) is dominated by the narrow oxo-Cr(V) signal, whereas this same feature has a much lower relative intensity for the same pigment mixed with the acrylic binder (red dotted line). The same signal is even weaker for the $\mathrm{CY}_{0}$-oil paint (blue dotted line) and it is almost undetectable for the equivalent acrylic sample (green dotted line). At the same time, the intensity of $\mathrm{Cr}$ (III)-signal is increased for all the samples and it is comparable in the $\mathrm{CY}_{0.8}$-oil and $\mathrm{CY}_{0.8}$-acrylic paints. The same spectral feature is weaker in the $\mathrm{CY}_{0}$-samples and in particular in the $\mathrm{CY}_{0}$-acrylic paint. As a whole, these findings indicate that $\mathrm{CY}_{0.8}$ has a higher propensity toward reduction as compared with $\mathrm{CY}_{0}$ and that this process is more significant in the oil than in the acrylic binder.

As summarized in Table 2, the trends of $\mathrm{Cr}(\mathrm{V}) / \mathrm{Cr}$ (III) signal ratios suggest that the natural aging leads to increasing formation of $\mathrm{Cr}(\mathrm{V})$-species in $\mathrm{CY}_{0.8}$ samples, whereas to $\mathrm{Cr}(\mathrm{III})$-species in $\mathrm{CY}_{0}$ paints. The highest $\mathrm{Cr}(\mathrm{V}) / \mathrm{Cr}(\mathrm{III})$ signal ratios for the oil paints with respect to the acrylic ones also indicate that the formation of $\mathrm{Cr}(\mathrm{V})$ is favored in the oil binder.

Only in the acrylic paints, an additional narrow and partially anisotropic signal around $g=2.013 \pm 0.002$ starts to be visible after 7 months and it is dominant for the $\mathrm{CY}_{0.8}$-acrylic sample (Figures $\mathrm{S} 1$ and $2 \mathrm{~B}$ ). The shape and position of this spectral feature are consistent with those of peroxy radicals $\left(\mathrm{ROO}^{\bullet}\right){ }^{45}$ which may form as an oxidation product of the acrylic matrix. ${ }^{46}$

To obtain information about the microscale length distribution of reduced chromium within the stratigraphy of the paint, SR-based $\mathrm{Cr}$ K-edge $\mu$-XANES investigations were performed on the touch dry and naturally aged $\mathrm{CY}_{0.8}$ samples.

Table 2. Temporal Evolution of the Estimated EPR Cr(V)/Cr(III) signal Ratio for Naturally Aged $\mathrm{CY}_{0}, \mathrm{CY}_{0.8}$, and $\mathrm{K}_{2} \mathrm{CrO}_{4} \mathrm{Oil}$ and Acrylic Paints

\begin{tabular}{|c|c|c|c|c|c|c|}
\hline \multirow[b]{2}{*}{ sample ${ }^{b}$} & \multicolumn{6}{|c|}{$\mathrm{Cr}(\mathrm{V}) / \mathrm{Cr}(\mathrm{III})^{a}$} \\
\hline & touch dry & 1 month & 4 months & 7 months & 8 months & 20 months \\
\hline $\mathrm{CY}_{0}$-acrylic & 0 & & & & $1.2 \pm 0.1 \times 10^{-4}$ & $5.4 \pm 0.1 \times 10^{-5}$ \\
\hline $\mathrm{CY}_{0}-\mathrm{oil}$ & 0 & & & & $4.1 \pm 0.1 \times 10^{-4}$ & $1.0 \pm 0.1 \times 10^{-4}$ \\
\hline $\mathrm{CY}_{0.8}$-acrylic & 0 & & & & $<10^{-5}$ & $3.05 \pm 0.03 \times 10^{-4}$ \\
\hline $\mathrm{CY}_{0.8}-\mathrm{oil}$ & $4.2 \pm 0.2 \times 10^{-4}$ & & & & $5 \pm 1 \times 10^{-4}$ & $1.31 \pm 0.02 \times 10^{-3}$ \\
\hline $\mathrm{K}_{2} \mathrm{CrO}_{4}-$ oil & & $1.6 \pm 0.2 \times 10^{-3}$ & $6.2 \pm 0.5 \times 10^{-4}$ & $4.7 \pm 0.4 \times 10^{-4}$ & & \\
\hline $\mathrm{K}_{2} \mathrm{CrO}_{4}$-acrylic & & $1.2 \pm 0.2 \times 10^{-4}$ & & $6.2 \pm 0.6 \times 10^{-4}$ & & \\
\hline
\end{tabular}

${ }^{a}$ Measurements were performed at different aging times due to the faster tendency toward discoloration/reduction of $\mathrm{K}_{2} \mathrm{CrO}{ }_{4}$ with respect to $\mathrm{CY}$ pigments in both binders, especially in oil (see Sections 3.1.1 and 3.2 for further details). ${ }^{b}$ Analysis of the "pure" $\mathrm{CY}_{0}, \mathrm{CY}_{0.8}$, and $\mathrm{K}_{2} \mathrm{CrO}_{4}$ powders (i.e., not mixed with the binder) did not reveal the presence of any EPR signals (spectra not reported), due to the diamagnetic character of Cr(VI)species. 
As shown by the LCF results of Tables S1,S2 (Supporting Information; see also Section 2.2.3 for further details), the presence of reduced Cr-species (between 10 and 20\%) is mainly localized in the uppermost $3-5 \mu \mathrm{m}$ of $\mathrm{CY}_{0.8}-$ oil and $\mathrm{CY}_{0.8}$-acrylic thin sections, whereas mainly $\mathrm{Cr}(\mathrm{VI})$-species (above 90\%) were detected in the profiles collected at depth greater than $5 \mu \mathrm{m}$. In the XANES spectra (Figure 3; only a

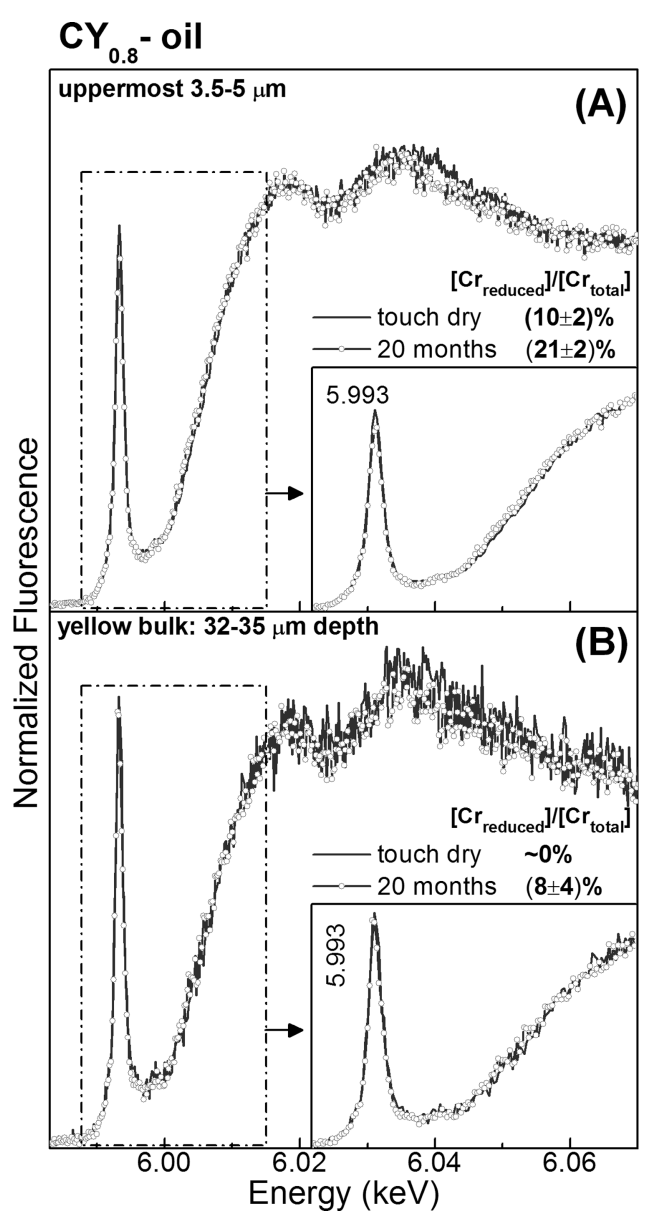

Figure 3. Comparison between a selection of the Cr K-edge $\mu$ XANES spectra acquired from thin sections of the touch dry (solid lines) and the 20 months naturally aged (dotted lines) $\mathrm{CY}_{0.8}$-oil paints. (A): spectra obtained from the uppermost 3.5-5 $\mu \mathrm{m}$ of the paints; (B): spectra recorded from the yellow bulk paint at depth values greater than $30 \mu \mathrm{m}$ [see Tables S1 and S2 (Supporting Information) for further details about the LCF results and equivalent data recorded from thin sections of $\mathrm{CY}_{0.8}$-acrylic samples].

selection of the most representative spectra of $\mathrm{CY}_{0.8}$-oil paints is shown), the presence of reduced $\mathrm{Cr}$ compounds is demonstrated by the shift of the absorption edge toward lower energies and a decrease of the intensity of the Cr preedge peak located at about $5.993 \mathrm{keV}$. Notably, for $\mathrm{CY}_{0.8}-$ oil samples, the reduced chromium abundance measured by XANES follows a trend similar to that obtained by EPR (Figure 2 and Table 1): it increases with increasing natural aging time, ranging from about 10 to $20 \%$ for the touch dry and 20 months naturally aged paints, respectively (Figure $3 \mathrm{~A}$ and Table S1). Unlike the EPR data, no significant difference was instead observed in the reduced $\mathrm{Cr}$ relative amount of $\mathrm{CY}_{0.8}$-acrylic paints, which keeps a value of about $10 \%$ for the touch dry and the naturally aged samples (Table S2; spectra not reported).

3.1.2. Photochemically Aged CY Mock-Up Paints. Figure $1 \mathrm{~A}, \mathrm{~B}$ (right side) illustrates the photographs of the $\mathrm{CY}_{0}$ and $\mathrm{CY}_{0.8}$ paints in mixture with either linseed oil or acrylic after exposure to UVA-Visible light. As expected, ${ }^{14,18} \mathrm{CY}_{0.8}$ paints reveal a more significant darkening than $\mathrm{CY}_{0}$ samples. Moreover, the extent of discoloration is higher in the oil mock-ups than in the acrylic paints. The visual observations were confirmed by diffuse reflectance UV-Vis spectroscopy (Figure 1C,D: black dotted lines): above $520 \mathrm{~nm}$, the spectra show a decrease of reflectance to a different extent. As summarized in Table 1 , these modifications can be expressed by a decrease of $L^{*}, a^{*}$ and $b^{*}$, the latter representing the largest contribution to $\Delta E^{*}$. Upon light exposure, the paint surface of $\mathrm{CY}_{0.8}$-oil paint changes color more significantly than the equivalent $\mathrm{CY}_{0.8}$-acrylic paint, reaching $\Delta E^{*}$ values of about 36 and 11, respectively. A much smaller but still appreciable color change took place in the photochemically aged $\mathrm{CY}_{0}-$ oil $\left(\Delta E^{*} \approx 6\right)$ and $\mathrm{CY}_{0}-$ acrylic samples $\left(\Delta E^{*} \approx\right.$ $5)$.

In order to further understand the different photochemical response of CYs in the two binding media, we performed EPR and $\mu$-XANES spectroscopy investigations of light-exposed $\mathrm{CY}_{0.8}$ paints.

Figure 4A shows the EPR spectra recorded before (solid lines) and after photochemical aging (dotted lines) of $\mathrm{CY}_{0.8}-$ oil and $\mathrm{CY}_{0.8}$-acrylic paints. In both samples, the light exposure promotes the formation of $\mathrm{Cr}$ (III)-compounds, as shown by the increase of the intensity of the broad band at $g \approx$ 2.01. In the aged $\mathrm{CY}_{0.8}-$ oil paint, the intensity of $\mathrm{Cr}(\mathrm{V})$-signal $(g \approx 1.980)$ also increases, but to a lesser extent than the $\mathrm{Cr}$ (III)-band intensity. In the photochemically $\mathrm{CY}_{0.8}-$ acrylic paint, the disappearing of the peroxy radical signal $(g \approx 2.013)$ occurs without formation of $\mathrm{Cr}(\mathrm{V})$-signals.

The quantitative $[\mathrm{Cr}(\mathrm{VI})] /\left[\mathrm{Cr}_{\text {total }}\right]$ and $\left[\mathrm{Cr}_{\text {reduced }}\right] /\left[\mathrm{Cr}_{\text {total }}\right]$ depth profiles obtained by LCF of the $\mu$-XANES spectra (Figure 4B) highlight that the abundance of reduced $\mathrm{Cr}$ is between 56 and $30 \%$ within the uppermost $7-8 \mu \mathrm{m}$ of the photochemically aged $\mathrm{CY}_{0.8}$-oil paint (see Figure S2A and Table S3 for further details about the fit results). These species are present in amounts of about $30 \%$ and are distributed as a 3 $\mu \mathrm{m}$ thick superficial layer in the aged $\mathrm{CY}_{0.8}$-acrylic mock-up (Figure S2B and Table S4). For both the light-exposed $\mathrm{CY}_{0.8}-$ oil and $\mathrm{CY}_{0.8}$-acrylic samples, the relative amount of reduced Cr decreases down to values of about $20-10 \%$ at depth values greater than $3 \mu \mathrm{m}$.

Overall, the above-discussed results show that the nature of the binding medium influences the tendency of $\mathrm{CY}$ pigments toward reduction both in the presence and absence of light, being less pronounced in the acrylic matrix. In the same binding medium, the extent of the reduction process (more pronounced in the uppermost $3-5 \mu \mathrm{m}$ of the paint) also depends on the nature of lead chromate-based compound, being favored when the pigment is present as $\mathrm{PbCr}_{0.2} \mathrm{~S}_{0.8} \mathrm{O}_{4}$.

To assess any possible correlation between the chromatebased pigment's solubility and its tendency toward (photo)chemical reduction in different organic binders, in the following section the results obtained from naturally aged $\mathrm{K}_{2} \mathrm{CrO}_{4}$ mock-up paints will be discussed.

3.2. Effects of the Pigment's Solubility. Figure 5 shows the photographs and the UV-Vis/colorimetric data obtained from $\mathrm{K}_{2} \mathrm{CrO}_{4}$-oil and $\mathrm{K}_{2} \mathrm{CrO}_{4}$-acrylic paints, after natural 


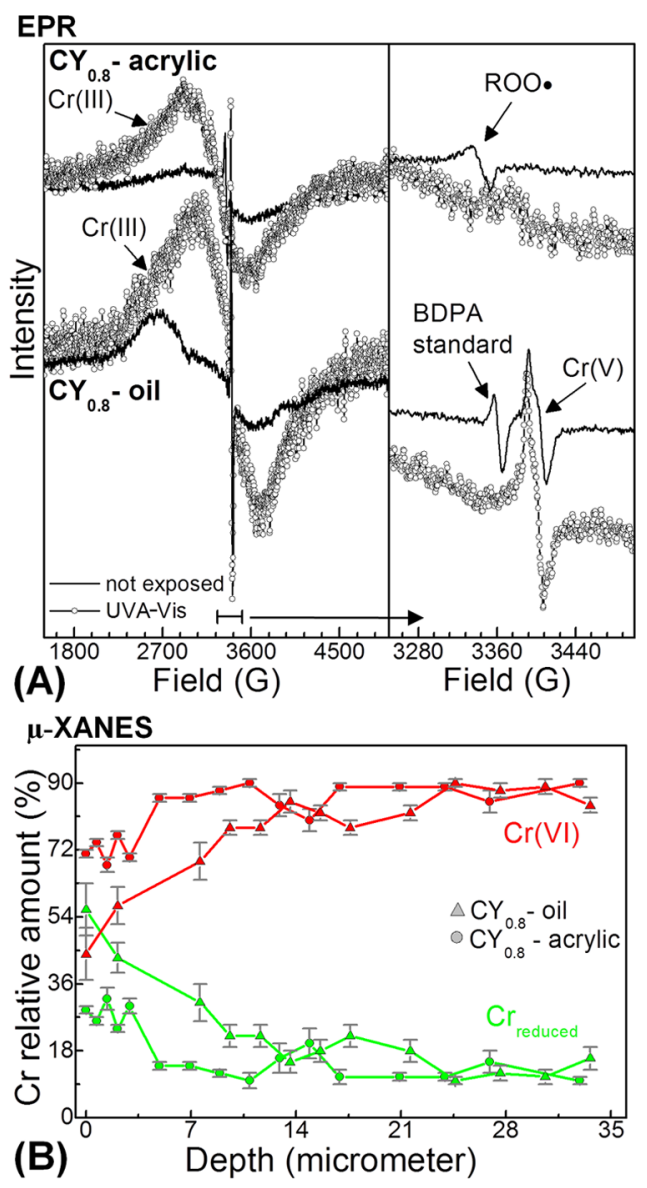

Figure 4. (A) Room-temperature $\mathrm{X}$-band $\mathrm{EPR}$ spectra of $\mathrm{CY}_{0.8}-$ acrylic (top) and $\mathrm{CY}_{0.8}$-oil (bottom) paints before (solid lines) and after UVA-Visible light exposure (dotted lines) $(\nu=9.428 \mathrm{GHz}$, power $=6.6 \mathrm{~mW}$, SHQ Bruker cavity with cryostat). (B) Quantitative (green) $\mathrm{Cr}_{\text {reduced }}$ and (red) $\mathrm{Cr}(\mathrm{VI})$ depth profiles obtained as a LCF of different Cr-reference compounds to the line of $\mu$-XANES spectra recorded from the photochemically aged $\mathrm{CY}_{0.8}$ paints: (triangles) oil and (circles) acrylic mock-ups [see Figure S2 and Tables S3,S4 (Supporting Information) for details].

aging up to 10 and 4 months, respectively. It is clearly apparent that a color change of the paint surface occurs as soon as $\mathrm{K}_{2} \mathrm{CrO}_{4}$ is mixed with oil, whereas it is not appreciable in the equivalent $\mathrm{K}_{2} \mathrm{CrO}_{4}$ mock-up prepared with the acrylic binder. The discoloration phenomenon is visible in the UV-Vis spectra (Figure 5C,D) through the decrease of reflectance in the $500-750 \mathrm{~nm}$ range. This variation is more strongly pronounced in the profiles recorded from the $\mathrm{K}_{2} \mathrm{CrO}_{4}$-oil sample (Figure 5C), where the intensity of a broad band centered at about $560 \mathrm{~nm}$ gradually increases with increasing natural aging time. In line with the literature, this spectral feature is ascribable to $\mathrm{Cr}(\mathrm{III})$-compounds. ${ }^{37}$ The corresponding colorimetric coordinates (Figure $5 \mathrm{E}$ ) show a progressive decrease of $L^{*}\left(\Delta L^{*}\right.$ : from $\approx-2$ to -22$)$ and $b^{*}\left(\Delta b^{*}\right.$ : from $\approx-1$ to -28$)$, which both give the greatest contribution to $\Delta E^{*}$, whereas an increase of a* was observed $\left(\Delta a^{*}\right.$ : from $\approx 2$ to 8$)$. The $\Delta E^{*}$ significantly increases with increasing aging time, reaching value up to about 36 . A just noticeable color difference was observed in the $\mathrm{K}_{2} \mathrm{CrO}_{4}$-acrylic sample, $\Delta E^{*}$ values being around 2-3 (Figure $5 \mathrm{~F}$ ).

The presence of both $\mathrm{Cr}(\mathrm{V})$-species (signal at $g \approx 1.980$ ) and $\mathrm{Cr}(\mathrm{III})$-species (broad feature at $g \approx 2.01$ ) is clearly visible in the EPR spectrum of the 1-month naturally aged $\mathrm{K}_{2} \mathrm{CrO}_{4}-$ oil paint (Figure 6A: red line). In line with the less-pronounced darkening observed for the equivalent $\mathrm{K}_{2} \mathrm{CrO}_{4}$-acrylic mockup, the intensity of the EPR signals due to reduced chromium is much lower in this sample (Figure 6A: black line). Notably, the $\mathrm{Cr}(\mathrm{V}) / \mathrm{Cr}(\mathrm{III})$ signal ratio estimated for the acrylic paint is of one order of magnitude smaller compared to that obtained for the oil sample (Table 2). Even by considering all the cautions necessary for a quantitative determination by EPR spectroscopy, a few considerations can be made on the absolute intensity of reduced $\mathrm{Cr}$ signals for the two samples: $\mathrm{Cr}(\mathrm{V})$ and $\mathrm{Cr}(\mathrm{III})$ bands are more intense by about 45 and 3 times, respectively, in the $\mathrm{K}_{2} \mathrm{CrO}_{4}$-oil paint with respect to the $\mathrm{K}_{2} \mathrm{CrO}_{4}$-acrylic mock-up. At the longest natural aging time (i.e., 7 months; Figure 6B) the absolute amount of reduced chromium is much larger in oil (red lines) than in acrylic (black lines) but with a $\mathrm{Cr}(\mathrm{V}) / \mathrm{Cr}(\mathrm{III})$ signal ratio which is comparable for the two samples (Table 2). Only the spectrum of the $\mathrm{K}_{2} \mathrm{CrO}_{4}$-acrylic paint shows the narrow signal assigned to peroxy radicals $(g \approx 2.013)$, which is the same as that present in the EPR spectra of naturally aged CY-acrylic paints (cf. Figure 2B and Section 3.1.1).

With the aim to obtain information about the stratigraphic distribution at the microscale of different $\mathrm{Cr}$-species, a $\mathrm{Cr} \mathrm{K}$ edge FF-XANES imaging experiment was carried out on thin sections of a 4 months naturally aged $\mathrm{K}_{2} \mathrm{CrO}_{4}$-oil paint and a 3 months naturally aged $\mathrm{K}_{2} \mathrm{CrO}_{4}-$ acrylic paint. As illustrated in the microphotographs of Figure 7A,B, a brownish layer of about $20 \mu \mathrm{m}$ thickness is particularly apparent only at the surface of the $\mathrm{K}_{2} \mathrm{CrO}_{4}$-oil sample. The corresponding quantitative $\mathrm{Cr}$ phase maps obtained by $\mathrm{Cr} \mathrm{K}$-edge $\mathrm{FF}-$ XANES imaging (Figure $7 \mathrm{C}$ ) reveal that $\mathrm{K}_{2} \mathrm{CrO}_{4}$ (red) is homogeneously present as the main component of the yellow paint, where it reaches relative abundance up to ca. 95\%; different $\mathrm{Cr}(\mathrm{III})$-compounds [i.e., $\mathrm{Cr}(\mathrm{OH})_{3} / \mathrm{Cr}_{2} \mathrm{O}_{3} /$ $\left.\left(\mathrm{CH}_{3} \mathrm{CO}_{2}\right)_{7} \mathrm{Cr}_{3}(\mathrm{OH})_{2}\right]$ (green) and a oxo-Cr(V)-compound [i.e., $\mathrm{NaCrO}_{5}\left(\mathrm{C}_{5} \mathrm{H}_{8} \mathrm{O}\right)_{2}$ ] (blue) are instead localized in the uppermost brownish layer, where they achieve relative amounts up to about 50 and $65 \%$, respectively (see Figure $S 3 A, B$ for a selection of the XANES spectra and the corresponding LCF results). A similar $\mathrm{Cr}(\mathrm{VI})$ - and $\mathrm{Cr}$ (III)compounds distribution is observable in the phase maps of the $\mathrm{K}_{2} \mathrm{CrO}_{4}$-acrylic paint (Figure 7D). Nevertheless, the thickness of the superficial alteration layer (less than $5 \mu \mathrm{m}$ ) and the corresponding relative abundance of reduced chromium (between 20 and 30\%; see Figure S3C for details) are much smaller than those detected in the $\mathrm{K}_{2} \mathrm{CrO}_{4}$-oil paint (Figure 7C).

To summarize, naturally aged $\mathrm{K}_{2} \mathrm{CrO}_{4}$ paints show a similar behavior as the equivalent ones prepared using lead chromatecompounds, revealing that the chromium reduction is more favored when the yellow powder is mixed with the oil than the acrylic binder and that is more significant at the paint surface.

In the same binding medium, our results also prove that the extent of chromate reduction is positively correlated with the solubility of the pigment, increasing in the following order: $\mathrm{PbCrO}_{4}<\mathrm{PbCr}_{0.2} \mathrm{~S}_{0.8} \mathrm{O}_{4}<\mathrm{K}_{2} \mathrm{CrO}_{4}$ (Figures 1, 2, and 5-7).

3.3. Chromate Reduction Mechanism in Different Binding Media. Within the boundaries of the employed experimental conditions, we found that the chromate reduction results from the interaction between the pigment and the binding medium and depends on the nature of the organic matrix. In linseed oil, the reduction of $\mathrm{Cr}(\mathrm{VI})$ gives rise to 
(A)
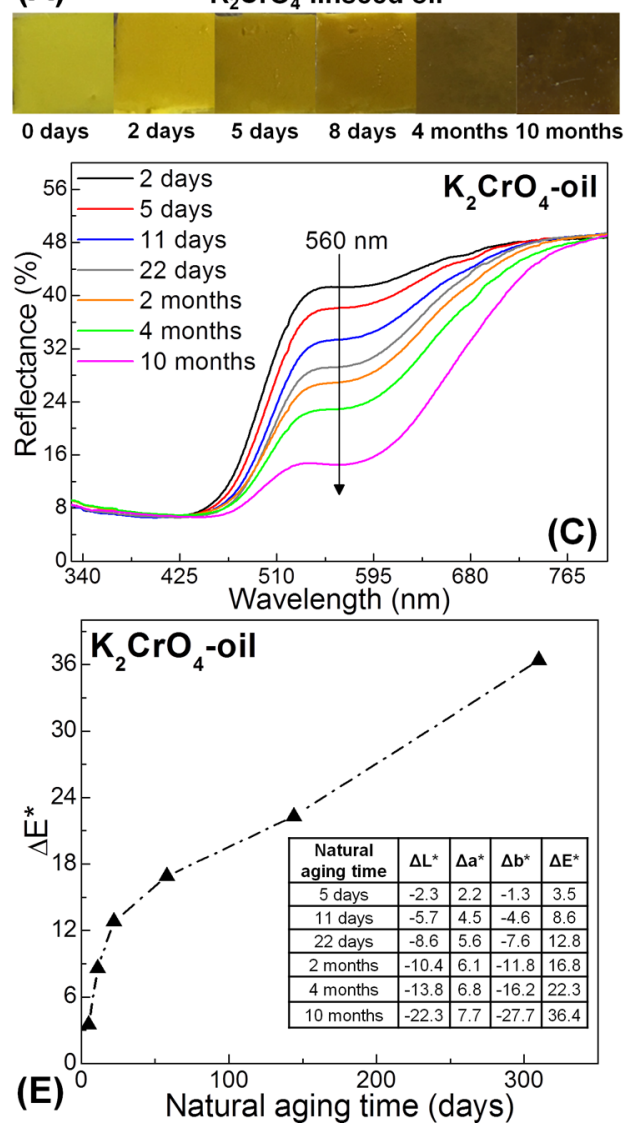

(B)
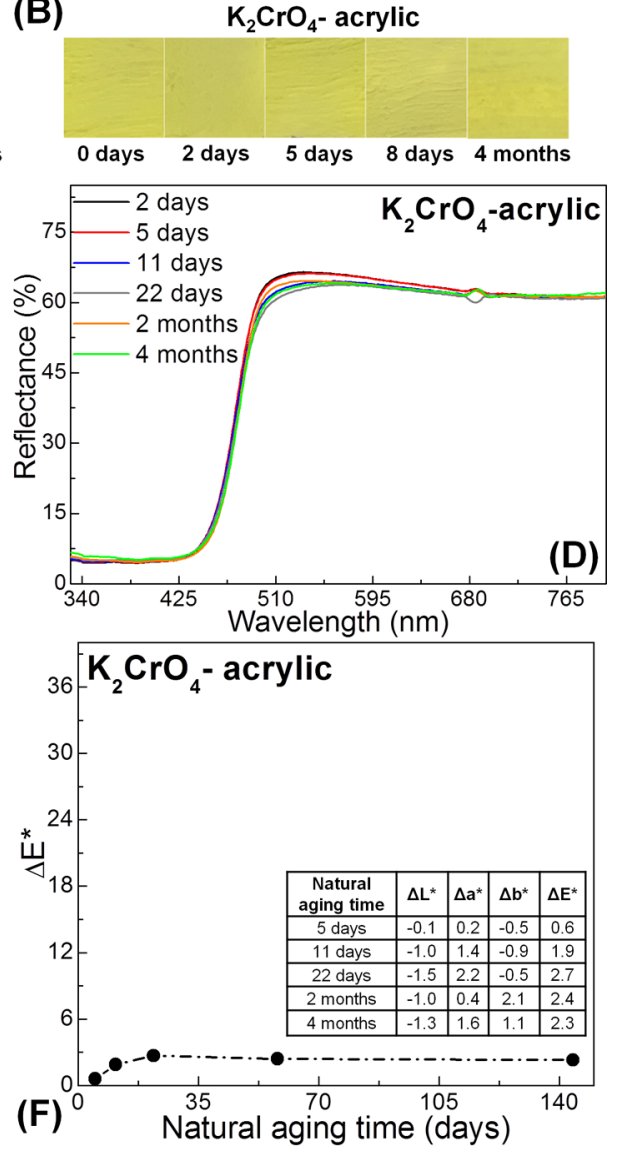

Figure 5. Photographs of naturally aged $\mathrm{K}_{2} \mathrm{CrO}_{4}$ mock-up paints obtained by using either (A) linseed oil $\left(\mathrm{K}_{2} \mathrm{CrO}_{4}-\right.$ oil $)$ or $(\mathrm{B})$ acrylic $\left(\mathrm{K}_{2} \mathrm{CrO}{ }_{4}-\right.$ acrylic) as binders. (C,D) Diffuse reflectance UV-Visible spectra and (E,F) plots of $\Delta E^{*}$ vs natural aging time of $\mathrm{K}_{2} \mathrm{CrO}_{4}-\mathrm{Oil}_{\text {and }} \mathrm{K}_{2} \mathrm{CrO}_{4}-\mathrm{acrylic}$ paints. Values in (E,D) report the change of colorimetric coordinates $L^{*}, a^{*}, b^{*}$ and the $\Delta E^{*}$ values with increasing natural aging time.

$\mathrm{Cr}(\mathrm{V})$ and $\mathrm{Cr}(\mathrm{III})$ species, whereas in acrylic, the reaction favors the formation of $\mathrm{Cr}$ (III), with a smaller amount of $\mathrm{Cr}(\mathrm{V})$-species and peroxy radicals that become detectable only after longer times of natural aging.

Based on our experimental findings and earlier research in the fields of $\mathrm{Cr}(\mathrm{VI})$-induced carcinogenicity, ${ }^{47-49}$ of carbon printing and of holography, ${ }^{38,39,50,51}$ a mechanism for the (photo)reduction of chromate-based pigments in the two different binding media can be put forward.

As a first step of the transformation, the chromate-based pigment releases $\mathrm{Cr}(\mathrm{VI})$ into the organic matrix. Afterward, these species undergo reduction, first to $\mathrm{Cr}(\mathrm{V})$ and then to $\mathrm{Cr}(\mathrm{III})$, according to the following general sequence of reactions (eqs 1 and 2$)^{47-49,52,53}$

$$
\begin{aligned}
& \mathrm{Cr}(\mathrm{VI})+\mathrm{B} \rightarrow \mathrm{Cr}(\mathrm{V})+\mathrm{P} \\
& \mathrm{Cr}(\mathrm{V})+\mathrm{B} \rightarrow \mathrm{Cr}(\mathrm{III})+\mathrm{P}
\end{aligned}
$$

where $\mathrm{B}$ is the organic binder that may act as one- or twoelectron donor and $\mathrm{P}$ denotes the oxidation product of $\mathrm{B}$. Depending on the local $\mathrm{pH}$ and the nature of the organic substrate, a pre-equilibrium step may precede the $\mathrm{Cr}(\mathrm{VI}) \rightarrow$ $\mathrm{Cr}(\mathrm{V})$ reduction step (eq 1), leading to the $\mathrm{Cr}(\mathrm{VI})-\mathrm{B}$ complex. ${ }^{4-49,53,54}$ Moreover, previous studies report that $\mathrm{Cr}(\mathrm{IV})$-intermediates may be also formed during the $\mathrm{Cr}(\mathrm{VI})$ $\rightarrow \mathrm{Cr}$ (III) reduction in the presence of organic substrates. ${ }^{53-57}$ However, under our experimental conditions, the identification of $\mathrm{Cr}(\mathrm{IV})$-compounds was not possible or challenging by EPR and XANES spectroscopies, respectively.

For explaining the different chemical reactivity of CYs either in the oil or the acrylic matrix, the different chemical properties (i.e., functional groups and $\mathrm{pH}$ ) and the nature of the drying process of the two binders have been considered.

In oil paints, $\mathrm{Cr}(\mathrm{VI})$ species are released both as $\mathrm{CrO}_{4}{ }^{2-}$ and $\mathrm{HCrO}_{4}{ }^{-}$due to the neutral/slight acidic nature of the binder. ${ }^{58}$ $\mathrm{HCrO}_{4}^{-}$anions may act as effective oxidants of the organic substrates due to the standard reduction potential of the $\mathrm{HCrO}_{4}^{-} / \mathrm{Cr}(\mathrm{III})$ redox couple $\left(0.79<E^{0 \prime}<0.56 \mathrm{~V}_{\mathrm{NHE}}, 4<\mathrm{pH}\right.$ $<7) .{ }^{59}$ It has been reported that in slightly acidic environments organic molecules containing one or more $\mathrm{COOH}$ and $\mathrm{OH}$ functional groups, such as $\alpha$-hydroxy/polyhydroxy (poly)carboxylic acids, ${ }^{43,54,56,57,60}$ saccharides, ${ }^{53,61,62}$ alcohols, ${ }^{55}$ are effective reductants and complexation agents for stabilizing labile $\mathrm{Cr}(\mathrm{V})$-intermediates. Thus, we can conclude that, during the drying process of linseed oil, stable oxo- $\mathrm{Cr}(\mathrm{V})$-complexes can be formed as the result of the interaction between $\mathrm{Cr}(\mathrm{VI})$ and $\mathrm{COOH}$ and $\mathrm{OH}$ functional groups of secondary products and intermediates of lipids oxidation, such as polycarboxylic acids, alcohols, hydroperoxides $(\mathrm{ROOH})$, and peroxy and alkoxyl radicals $\left(\mathrm{ROO}^{\bullet}, \mathrm{RO}^{\bullet}\right) .^{40,63,64}$ In a following step, the reduction process of $\mathrm{Cr}(\mathrm{V})$-complexes proceeds through interaction with the lipidic matrix, leading to $\mathrm{Cr}$ (III)compounds (possibly oxide and organo Cr-compounds) as final secondary products (Figures 1, 2, and 5-7). 

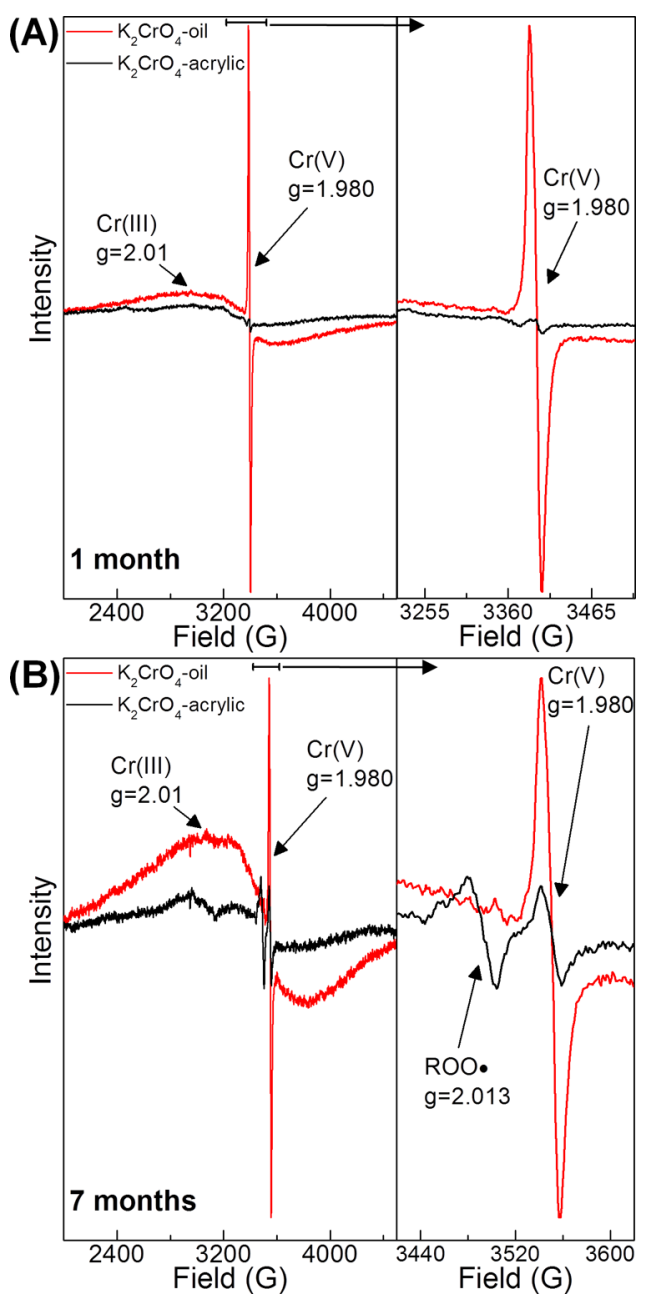

Figure 6. X-band EPR spectra for $\mathrm{K}_{2} \mathrm{CrO}_{4}$-oil (red lines) and (B) $\mathrm{K}_{2} \mathrm{CrO}_{4}$-acrylic (black lines) after natural aging for (A) 1 month $(\nu=$ $9.416 \mathrm{GHz}$, power $=6.7 \mathrm{~mW})$ and $(\mathrm{B}) 7$ months $(\nu=9.846 \mathrm{GHz}$, power $=6.7 \mathrm{~mW})$. The intensity of each spectrum is rescaled by the number of moles of chromium.

In acrylic paints, $\mathrm{Cr}(\mathrm{VI})$-species are released in the form of $\mathrm{CrO}_{4}{ }^{2-}$ ions into the organic matrix as a result of the alkaline $\mathrm{pH}$ of the medium ( 9.0). ${ }^{32,65}$ Upon these conditions, it is known that $\mathrm{Cr}(\mathrm{VI})$-species are weaker oxidizing agents $\left[E^{0 \prime} \mathrm{CrO}_{4}{ }^{2-} / \mathrm{Cr}(\mathrm{III})=0.36 \mathrm{~V}_{\mathrm{NHE}}, \mathrm{pH}=9.0\right]^{59}$ and that $\mathrm{Cr}(\mathrm{V})$-complexes may undergo disproportionation to yield $\mathrm{Cr}(\mathrm{III})$ and $\mathrm{Cr}(\mathrm{VI}){ }^{66}$ The formation/stabilization of $\mathrm{Cr}(\mathrm{V})$ compounds is also hindered by the intrinsic chemical composition of the acrylic binder that lacks of $\mathrm{COOH} / \mathrm{OH}$ groups. ${ }^{46,65,67}$ All these aspects contribute to rationalize our findings in acrylic paints (Figures 1, 2, and 5-7), providing an explanation of why chromate pigments show less tendency toward reduction and $\mathrm{Cr}(\mathrm{III})$-species are the main secondary products of the alteration process in the acrylic binder.

A surface passivation phenomenon can be invoked for explaining why the chromium reduction is more pronounced in the uppermost $5-20 \mu \mathrm{m}$ of both oil and acrylic paints (Figures 3 and 7). The phenomenon will contribute to decrease the permeability of environmental agents (e.g., moisture and oxygen) influencing the stability of the pigment and the binding medium, across the deepest regions of the paint. ${ }^{68,69}$ As a result, chemical changes will be favored for the components localized in the uppermost micrometers of the paint.

We have also demonstrated that the tendency of chromate toward reduction is activated by light exposure and is higher in oil paints than in the acrylic ones (Figures 1 and 4), with the formation of $\mathrm{Cr}(\mathrm{III})$-compounds as main secondary products. Based on our findings, light $(h \nu)$ may contribute in two different ways to the degradation process:

(i) by favoring the oxidation of the binding medium through the formation and decomposition of unstable hydroperoxides; ${ }^{30,46,63,65}$ subsequently, the corresponding oxidation products may act as electron donors for the $\mathrm{Cr}(\mathrm{VI})$ and $\mathrm{Cr}(\mathrm{V})$ reduction according to the scheme of eqs 1 and 2;

(ii) by producing light-activated $\mathrm{Cr}(\mathrm{VI})$-species that through interaction with the binder (B) yields the formation of a complex in the excited state (eq 3 ). This may then decay to $\mathrm{Cr}(\mathrm{V})$ and further undergo reduction to $\mathrm{Cr}(\mathrm{III})$, while the organic matrix is oxidized (eqs 4 and 5).

$$
\begin{aligned}
& \mathrm{Cr}(\mathrm{VI}) \stackrel{h \nu}{\longrightarrow} \mathrm{Cr}(\mathrm{VI})^{*} \stackrel{\mathrm{B}}{\rightarrow}[\mathrm{Cr}(\mathrm{VI}) \mathrm{B}]^{*} \\
& {[\mathrm{Cr}(\mathrm{VI}) \mathrm{B}]^{*} \rightarrow \mathrm{Cr}(\mathrm{V})+\mathrm{B}^{\bullet}} \\
& \mathrm{Cr}(\mathrm{V})+\mathrm{B} \stackrel{h \nu}{\longrightarrow} \mathrm{Cr}(\mathrm{III})+\mathrm{P}
\end{aligned}
$$

According to previous studies, ${ }^{50,51}$ the formation of the $\mathrm{Cr}(\mathrm{VI})$-complex (eq 3) usually involves $-\mathrm{COOH}$ and/or $-\mathrm{OH}$ functional groups of $\mathrm{B}$, with $-\mathrm{COOH}$ favoring the formation of $\mathrm{Cr}$ (III)-compounds (eq 5) and the $-\mathrm{OH}$ able to stabilize intermediate $\mathrm{Cr}(\mathrm{V})$-species (eq 4). Thus, based on (i) and (ii), we conclude that the chemical properties of the acrylic binder along with its lower tendency to undergo photooxidation with respect to linseed oil justify the increased stability of chromate pigments and the formation of only $\mathrm{Cr}$ (III)-compounds (Figure 4) in light-exposed acrylic paint films.

\section{CONCLUSIONS}

In this work, the combination of SR-based Cr K-edge XANES, $\mathrm{EPR}$, and UV-Vis spectroscopy measurements allowed us to elucidate the effects of a selection of binding media (i.e., linseed oil and acrylic) and of the solubility of different lead chromate-based yellows on the overall degradation process of this class of pigments. Within the boundaries of our experimental conditions, the study of naturally and photochemically aged $\mathrm{PbCrO}_{4}, \mathrm{PbCr}_{0.2} \mathrm{~S}_{0.8} \mathrm{O}_{4}$, and $\mathrm{K}_{2} \mathrm{CrO}_{4}$ mock-up paints led us to draw the following conclusions:

(1) The chromate reduction results from the interaction of the pigment with the binder, already starting with the drying of the paint film and continuing during its natural aging, without the need of exposure to light.

(2) The reduction pathways depend on the chemical properties (i.e., functional groups and $\mathrm{pH}$ ) and drying process of the binding medium, being more favored in the oil than in the acrylic binder. In oil paints, the neutral/slight acidic nature of the binder as well as the availability of $-\mathrm{COOH}$ and $-\mathrm{OH}$ functional groups of secondary products and intermediates of lipids oxidation promotes the formation and stabilization of oxo- $\mathrm{Cr}(\mathrm{V})$ complexes, which then can be further reduced to $\mathrm{Cr}$ (III)-compounds. In acrylic paints, the basic $\mathrm{pH}$ along with the lack of $-\mathrm{COOH}$ and $-\mathrm{OH}$ groups in the 

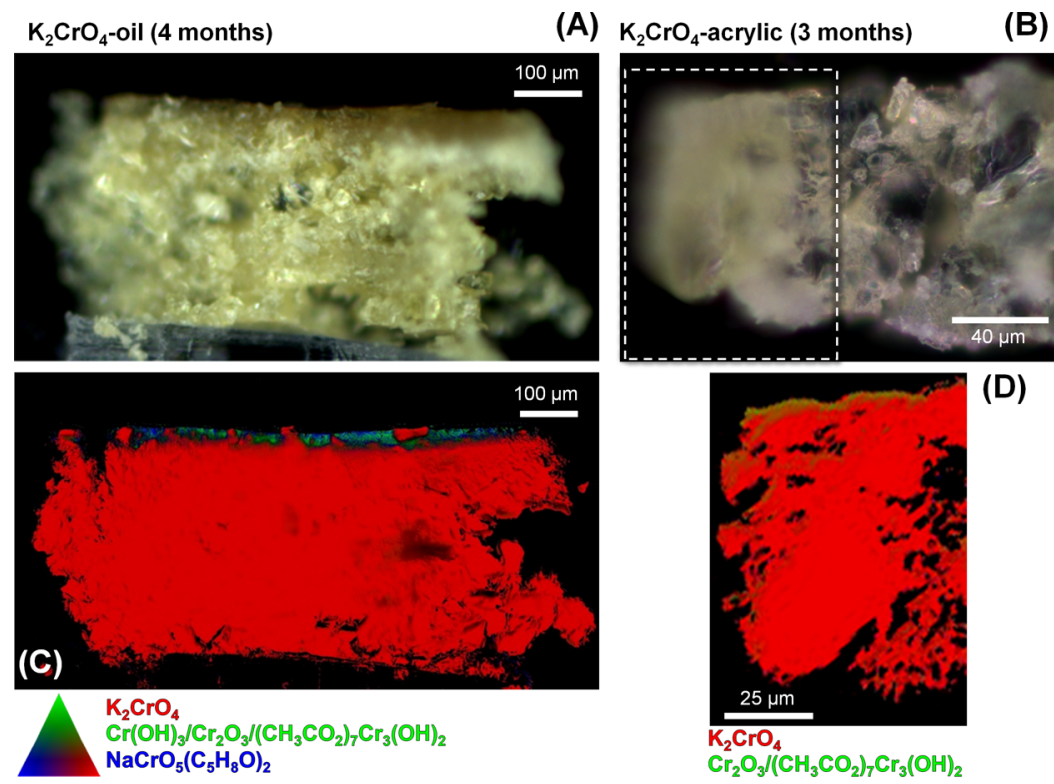

(D)

Figure 7. (A) Microphotographs of thin sections obtained from a naturally aged (A) $\mathrm{K}_{2} \mathrm{CrO}_{4}$-oil paint (4 months) and (B) $\mathrm{K}_{2} \mathrm{CrO}_{4}-$ acrylic paint (3 months). (C,D) Corresponding quantitative Cr phase maps obtained from the LCF of the Cr K-edge FF-XANES stack using the spectra of (red) $\mathrm{K}_{2} \mathrm{CrO}_{4}$, (green) $\mathrm{Cr}(\mathrm{OH})_{3} / \mathrm{Cr}_{2} \mathrm{O}_{3} /\left(\mathrm{CH}_{3} \mathrm{CO}_{2}\right)_{7} \mathrm{Cr}_{3}(\mathrm{OH})_{2}$ and (blue) $\mathrm{NaCrO}_{5}\left(\mathrm{C}_{5} \mathrm{H}_{8} \mathrm{O}\right)_{2}$ as references [see Figure $\mathrm{S} 3$ (Supporting Information) for details].

organic network hinders the formation of $\mathrm{Cr}(\mathrm{V})$ compounds, giving rise to $\mathrm{Cr}(\mathrm{III})$-species as main secondary products of the reduction process of the original chromate pigment.

(3) Upon light exposure, the tendency toward reduction of the less lightfast $\mathrm{PbCr}_{0.2} \mathrm{~S}_{0.8} \mathrm{O}_{4}$ is much lower in the acrylic binder, compared to the oil. The photochemical process leads to an increase in the relative abundance of $\mathrm{Cr}$ (III)-compounds in both binders.

(4) In the same binding medium, $\mathrm{PbCr}_{0.2} \mathrm{~S}_{0.8} \mathrm{O}_{4}$ undergoes reduction more readily than $\mathrm{PbCrO}_{4}$; the process becomes even more significant in $\mathrm{K}_{2} \mathrm{CrO}_{4}$ paints. This finding can be traced back to the solubility of the pigment in the binder, which increases in the same order (i.e., $\mathrm{PbCrO}_{4}<\mathrm{PbCr}_{0.2} \mathrm{~S}_{0.8} \mathrm{O}_{4}<\mathrm{K}_{2} \mathrm{CrO}_{4}$ ).

Our findings have important implications for the assessment of the degradation phenomenon of lead chromate-based pigments in artworks. We know that not only drying oils but also other types of binding media, including gums, waxes, as well as oleoresinous and proteinaceous materials, ${ }^{70-73}$ were frequently employed as binding media for chrome yellows. Thus, it becomes relevant to pay attention not only to the $\mathrm{Cr}$ / $\mathrm{S}$ stoichiometry and crystalline structure of the chrome yellow pigment but also to the chemical nature of the binder that is mixed with it.

Our results are also expected to contribute to a more indepth understanding of the degradation processes of other chromate-based yellow artists' pigments with different crystalline structures and solubility in water, such as those of zinc $\left(\mathrm{K}_{2} \mathrm{O} \cdot 4 \mathrm{ZnCrO}_{4} \cdot 3 \mathrm{H}_{2} \mathrm{O}\right){ }^{74,75}$ cadmium $\left[\mathrm{KCd}_{2}\left(\mathrm{CrO}_{4}\right)_{2}\right.$ $\left.\left(\mathrm{H}_{3} \mathrm{O}_{2}\right)\right]$, ${ }^{76}$ barium $\left(\mathrm{BaCrO}_{4}\right)$, and strontium $\left(\mathrm{SrCrO}_{4}\right)^{77}$

Questions remain open about the nature of the secondary products of the organic binder and the effects of other binding media on the reduction process of different chrome yellow types. Thus, further research is required in the future to systematically investigate these aspects. Additional studies will be also necessary for determining the solubility of chromate based-pigments in different binding media.

\section{ASSOCIATED CONTENT}

\section{S Supporting Information}

The Supporting Information is available free of charge on the ACS Publications website at DOI: 10.1021/acsomega.8b03669.

EPR spectroscopy data of naturally aged $\mathrm{CY}_{0.8}$ $\left(\mathrm{PbCr}_{0.2} \mathrm{~S}_{0.8} \mathrm{O}_{4}\right)$ paints; $\mu$-XANES spectroscopy at $\mathrm{Cr}$ K-edge of paints; and additional details about the linear combination fit results of the XANES data (PDF)

\section{AUTHOR INFORMATION}

\section{Corresponding Author}

*E-mail: letizia.monico@unipg.it.

\section{ORCID}

Letizia Monico: 0000-0001-9489-7805

Lorenzo Sorace: 0000-0003-4785-1331

\section{Notes}

The authors declare no competing financial interest.

\section{ACKNOWLEDGMENTS}

The research was financially supported by the European research project IPERION-CH, funded by the European Commission, H2020-INFRAIA-2014-2015 (grant agreement n. 654028), and by the project AMIS, within the program Dipartimenti di Eccellenza 2018-2022, funded by MIUR and University of Perugia. The University of Perugia is also acknowledged for financial support under the program "Ricerca di Base 2017". L.S. acknowledges the financial support of Ente CRF. For the beamtime grants received, we thank the ESRF (experiment no. HG64 and in-house beamtimes). 


\section{REFERENCES}

(1) Kühn, H.; Curran, M. Chrome Yellow and other Chromate Pigments. In Artists' Pigments: A Handbook of Their History and Characteristics, 2nd ed.; Feller, R. L., Ed.; National Gallery of Art: Washington D.C. and Archetype Publication: London, 2012; Vol 1; pp 187-200.

(2) Crane, M. J.; Leverett, P.; Shaddick, L. R.; Williams, P. A.; Kloprogge, J. T.; Frost, R. L. N. Jb. Miner. Mh. 2001, 11, 505-519.

(3) Monico, L.; Janssens, K.; Miliani, C.; Brunetti, B. G.; Vagnini, M.; Vanmeert, F.; Falkenberg, G.; Abakumov, A.; Lu, Y.; Tian, H.; Verbeeck, J.; Radepont, M.; Cotte, M.; Hendriks, E.; Geldof, M.; van der Loeff, L.; Salvant, J.; Menu, M. Degradation Process of Lead Chromate in Paintings by Vincent van Gogh Studied by Means of Spectromicroscopic Methods. 3. Synthesis, Characterization, and Detection of Different Crystal Forms of the Chrome Yellow Pigment. Anal. Chem. 2013, 85, 851-859, and references therein.

(4) Monico, L.; Janssens, K.; Hendriks, E.; Brunetti, B. G.; Miliani, C. Raman study of different crystalline forms of $\mathrm{PbCrO}_{4}$ and $\mathrm{PbCr}_{1-x} \mathrm{~S}_{\mathrm{x}} \mathrm{O}_{4}$ solid solutions for the noninvasive identification of chrome yellows in paintings: a focus on works by Vincent van Gogh. J. Raman Spectrosc. 2014, 45, 1034-1045, and references therein.

(5) Wilson, M.; Wyld, M.; Roy, A. Natl. Gallery Tech. Bull. 1981, 5, $14-25$.

(6) Dredge, P.; Wuhrer, R.; Phillips, M. R. Monet's Painting under the Microscope. Microsc. Microanal. 2003, 9, 139-143.

(7) Roy, A. Natl. Gallery Tech. Bull. 2007, 28, 58-68.

(8) Daher, C.; Sutherland, K.; Stratis, H.; Casadio, F. Paul Gauguin's Noa Noa prints: Multi-analytical characterization of the printmaking techniques and materials. Microchem. J. 2018, 138, 348-359.

(9) Defeyt, C.; Van Vyve, E.; Leen, F.; Vandepitte, F.; Gilbert, B.; Herens, E.; Strivay, D. Heritage Sci. 2018, 6, 20.

(10) Vanmeert, F.; Hendriks, E.; Van der Snickt, G.; Monico, L.; Dik, J.; Janssens, K. Chemical Mapping by Macroscopic X-ray Powder Diffraction (MA-XRPD) of Van Gogh's Sunflowers: Identification of Areas with Higher Degradation Risk. Angew. Chem., Int. Ed. 2018, 57, $7418-7422$.

(11) Monico, L.; Janssens, K.; Hendriks, E.; Vanmeert, F.; Van der Snickt, G.; Cotte, M.; Falkenberg, G.; Brunetti, B. G.; Miliani, C. Evidence for Degradation of the Chrome Yellows in Van Gogh's Sunflowers: A Study Using Noninvasive In Situ Methods and Synchrotron-Radiation-Based X-ray Techniques. Angew. Chem., Int. Ed. 2015, 54, 13923-13927, and references therein.

(12) Fiedler, I. La Grande Jatte: A Study of the Materials and Technique. In Seurat and the Making of La Grande Jatte; Herbert, R. L., Ed.; The Art Institute of Chicago: Chicago and University of California Press: Berkeley, 2004; pp 196-213.

(13) Kirby, J.; Stonor, K.; Roy, A.; Burnstock, A.; Grout, R.; White, R. Natl. Gallery Tech. Bull. 2003, 24, 4-37.

(14) Monico, L.; Janssens, K.; Cotte, M.; Romani, A.; Sorace, L.; Grazia, C.; Brunetti, B. G.; Miliani, C. Synchrotron-based X-ray spectromicroscopy and electron paramagnetic resonance spectroscopy to investigate the redox properties of lead chromate pigments under the effect of visible light. J. Anal. At. Spectrom. 2015, 30, 1500-1510.

(15) Monico, L.; Janssens, K.; Cotte, M.; Sorace, L.; Vanmeert, F.; Brunetti, B. G.; Miliani, C. Chromium speciation methods and infrared spectroscopy for studying the chemical reactivity of lead chromate-based pigments in oil medium. Microchem. J. 2016, 124, $272-282$.

(16) Monico, L.; Van der Snickt, G.; Janssens, K.; De Nolf, W.; Miliani, C.; Verbeeck, J.; Tian, H.; Tan, H.; Dik, J.; Radepont, M.; Cotte, M. Degradation Process of Lead Chromate in Paintings by Vincent van Gogh Studied by Means of Synchrotron X-ray Spectromicroscopy and Related Methods. 1. Artificially Aged Model Samples. Anal. Chem. 2011, 83, 1214-1223.

(17) Tan, H.; Tian, H.; Verbeeck, J.; Monico, L.; Janssens, K.; Van Tendeloo, G. Nanoscale Investigation of the Degradation Mechanism of a Historical Chrome Yellow Paint by Quantitative Electron Energy Loss spectroscopy Mapping of Chromium Species. Angew. Chem., Int. Ed. 2013, 52, 11360-11363.
(18) Monico, L.; Janssens, K.; Miliani, C.; Van der Snickt, G.; Brunetti, B. G.; Cestelli Guidi, M.; Radepont, M.; Cotte, M. Degradation Process of Lead Chromate in Paintings by Vincent van Gogh Studied by Means of Spectromicroscopic Methods. 4. Artificial Aging of Model Samples of Co-Precipitates of Lead Chromate and Lead Sulfate. Anal. Chem. 2013, 85, 860-867.

(19) Otero, V.; Carlyle, L.; Vilarigues, M.; Melo, M. J. Chrome yellow in nineteenth century art: historic reconstructions of an artists' pigment. RSC Adv. 2012, 2, 1798-1805.

(20) Otero, V.; Pinto, J. V.; Carlyle, L.; Vilarigues, M.; Cotte, M.; Melo, M. J. Nineteenth century chrome yellow and chrome deep from Winsor \& NewtonTM. Stud. Conserv. 2017, 62, 123-149.

(21) Otero, V.; Vilarigues, M.; Carlyle, L.; Cotte, M.; De Nolf, W.; Melo, M. J. A little key to oxalate formation in oil paints: protective patina or chemical reactor? Photochem. Photobiol. Sci. 2018, 17, 266270.

(22) Monico, L.; Janssens, K.; Alfeld, M.; Cotte, M.; Vanmeert, F.; Ryan, C. G.; Falkenberg, G.; Howard, D. L.; Brunetti, B. G.; Miliani, C. Full spectral XANES imaging using the Maia detector array as a new tool for the study of the alteration process of chrome yellow pigments in paintings by Vincent van Gogh. J. Anal. At. Spectrom. 2015, 30, 613-626.

(23) Monico, L.; Janssens, K.; Vanmeert, F.; Cotte, M.; Brunetti, B. G.; Van der Snickt, G.; Leeuwestein, M.; Salvant Plisson, J.; Menu, M.; Miliani, C. Degradation Process of Lead Chromate in Paintings by Vincent van Gogh Studied by Means of Spectromicroscopic Methods. Part 5. Effects of Nonoriginal Surface Coatings into the Nature and Distribution of Chromium and Sulfur Species in Chrome Yellow Paints. Anal. Chem. 2014, 86, 10804-10811.

(24) Monico, L.; Van der Snickt, G.; Janssens, K.; De Nolf, W.; Miliani, C.; Dik, J.; Radepont, M.; Hendriks, E.; Geldof, M.; Cotte, M. Degradation Process of Lead Chromate in Paintings by Vincent van Gogh Studied by Means of Synchrotron X-ray Spectromicroscopy and Related Methods. 2. Original Paint Layer Samples. Anal. Chem. 2011, $83,1224-1231$

(25) Muñoz-García, A. B.; Massaro, A.; Pavone, M. Ab initio study of $\mathrm{PbCr}_{(1-\mathrm{x})} \mathrm{S}_{\mathrm{x}} \mathrm{O}_{4}$ solid solution: an inside look at Van Gogh Yellow degradation. Chem. Sci. 2016, 7, 4197-4203.

(26) Amat, A.; Miliani, C.; Fantacci, S. Structural and electronic properties of the $\mathrm{PbCrO}_{4}$ chrome yellow pigment and of its light sensitive sulfate-substituted compounds. RSC Adv. 2016, 6, 3633636344.

(27) Rahemi, V.; Sarmadian, N.; Anaf, W.; Janssens, K.; Lamoen, D.; Partoens, B.; De Wael, K. Unique Optoelectronic Structure and Photoreduction Properties of Sulfur-Doped Lead Chromates Explaining Their Instability in Paintings. Anal. Chem. 2017, 89, 3326-3334.

(28) Wilbur, S.; Abadin, H.; Fay, M.; Yu, D.; Tencza, B.; Ingerman, L.; Klotzbach, J.; James, S. Toxicological Profile for Chromium; Agency for Toxic Substances and Disease Registry (US): Atlanta (GA), 2012; and references therein.

(29) Montaldi, A.; Zentilin, L.; Zordan, M.; Bianchi, V.; Levis, A. G.; Clonfero, E.; Paglialunga, S. Chromosomal effects of heavy metals $(\mathrm{Cd}, \mathrm{Cr}, \mathrm{Hg}, \mathrm{Ni}$ and $\mathrm{Pb})$ on cultured mammalian cells in the presence of nitrilotriacetic acid (NTA). Toxicol. Environ. Chem. 1987, 14, 183200.

(30) Lazzari, M.; Chiantore, O. Drying and oxidative degradation of linseed oil. Polym. Degrad. Stab. 1999, 65, 303-313.

(31) Chiantore, O.; Scalarone, D.; Learner, T. Characterization of Artists' Acrylic Emulsion Paints. Int. J. Polym. Anal. Charact. 2003, 8, 67-82.

(32) Jablonski, E.; Learner, T.; Hayes, J.; Golden, M. Conservation concerns for acrylic emulsion paints. Stud. Conserv. 2003, 48, 3-12.

(33) Cotte, M.; Pouyet, E.; Salomé, M.; Rivard, C.; De Nolf, W.; Castillo-Michel, H.; Fabris, T.; Monico, L.; Janssens, K.; Wang, T.; Sciau, P.; Verger, L.; Cormier, L.; Dargaud, O.; Brun, E.; Bugnazet, D.; Fayard, B.; Hesse, B.; Pradas del Real, A. E.; Veronesi, G.; Langlois, J.; Balcar, N.; Vandenberghe, Y.; Solé, V. A.; Kieffer, J.; Barrett, R.; Cohen, C.; Cornu, C.; Baker, R.; Gagliardini, E.; Papillon, E.; Susini, J. The ID21 X-ray and infrared microscopy beamline at the 
ESRF: status and recent applications to artistic materials. J. Anal. At. Spectrom. 2017, 32, 477-493.

(34) Ravel, B.; Newville, M. ATHENA, ARTEMIS, HEPHAESTUS: data analysis for X-ray absorption spectroscopy using IFEFFIT. $J$. Synchrotron Radiat. 2005, 12, 537-541.

(35) Liu, Y.; Meirer, F.; Williams, P. A.; Wang, J.; Andrews, J. C.; Pianetta, P. TXM-Wizard: a program for advanced data collection and evaluation in full-field transmission X-ray microscopy. Synchrotron Radiat. 2012, 19, 281-287.

(36) Bertrand, L.; Schöeder, S.; Anglos, D.; Breese, M. B. H.; Janssens, K.; Moini, M.; Simon, A. Mitigation strategies for radiation damage in the analysis of ancient materials. TrAC, Trends Anal. Chem. 2015, 66, 128-145.

(37) Weckhuysen, B. M.; Wachs, I. E.; Schoonheydt, R. A. Surface Chemistry and Spectroscopy of Chromium in Inorganic Oxides. Chem. Rev. 1996, 96, 3327-3350.

(38) Pizzocaro, C.; Lafond, C.; Bolte, M. Dichromated polyvinylalcohol: key role of chromium $(\mathrm{V})$ in the properties of the photosensitive material. J. Photochem. Photobiol., A 2002, 151, 221228.

(39) Lafond, C.; Pizzocaro, C.; Lessard, R. A.; Bolte, M. Opt. Eng. 2000, 39, 610-616.

(40) Mallegol, J.; Lemaire, J.; Gardette, J. L. Yellowing of Oil-Based Paints. Stud. Conserv. 2001, 46, 121-131.

(41) Smith, G. D. Aging characteristics of a contemporary emulsion used in artists' paints. In Modern paints uncovered, proceedings from the modern paints uncovered symposium; Learner, T. J. S., Smithen, P., Krueger, J. W., Schilling, M. R., Eds.; Getty Publications: Los Angeles, 2007; pp 236-246.

(42) Farrell, R. P.; Lay, P. A. New Insights into the Structures and Reactions of Chromium(V) Complexes: Implications for Chromium(VI) and Chromium(V) Oxidations of Organic Substrates and the Mechanisms of Chromium-Induced Cancers. Comments Inorg. Chem. 1992, 13, 133-175.

(43) Zhang, L.; Lay, P. A. EPR Spectroscopic Studies of the Reactions of $\mathrm{Cr}(\mathrm{VI})$ with 1-Ascorbic Acid, 1-Dehydroascorbic Acid, and 5,6-O-Isopropylidene-1-ascorbic Acid in Water. ${ }^{1}$ Implications for Chromium(VI) Genotoxicity. J. Am. Chem. Soc. 1996, 118, 1262412637.

(44) Nagi, M. K.; Harton, A.; Donald, S.; Lee, Y. S.; Sabat, M.; O'Connor, C. J.; Vincent, J. B. An Unsymmetric Trinuclear Chromium(III) Oxo Carboxylate Assembly: Structure and Characterization of $\mathrm{Cr}_{3} \mathrm{O}\left(\mathrm{O}_{2} \mathrm{CPh}\right)_{4}(8 \text {-hqn })_{3} \cdot 1.25 \mathrm{CH}_{2} \mathrm{Cl}_{2}$. Inorg. Chem. 1995, 34, 3813-3820.

(45) Hori, Y.; Shimada, S.; Kashiwabara, H. E.s.r. studies of peroxy radicals in polyethylene: 1 . Temperature dependence of spectra and molecular motion of radical sites. Polymer 1977, 18, 567-572.

(46) Fox, R. B.; Isaacs, L. G.; Stokes, S.; Kagarise, R. E. Photodegradation of poly(methyl acrylate). J. Polym. Sci., Part A: Gen. Pap. 1964, 2, 2085-2092.

(47) Mitewa, M.; Bontchev, P. R. Chromium(V) coordination chemistry. Coord. Chem. Rev. 1985, 61, 241-272, and references therein.

(48) Farrell, R. P.; Lay, P. A. New Insights into the Structures and Reactions of Chromium(V) Complexes: Implications for Chromium(VI) and Chromium(V) Oxidations of Organic Substrates and the Mechanisms of Chromium-Induced Cancers. Comments Inorg. Chem. 1992, 13, 133-175, and references therein.

(49) Codd, R.; Dillon, C. T.; Levina, A.; Lay, P. A. Studies on the genotoxicity of chromium: from the test tube to the cell. Coord. Chem. Rev. 2001, 216-217, 537-582, and references therein.

(50) Barichard, A.; Israëli, Y.; Rivaton, A. Photocrosslinking in dichromated poly(acrylic acid) during hologram recording and comparison with dichromated poly(vinyl alcohol). J. Polym. Sci., Part A: Polym. Chem. 2008, 46, 636-642.

(51) Manivannan, G.; Changkakoti, R.; Lessard, R. A.; Mailhot, G.; Bolte, M. Primary photoprocesses of chromium(VI) in real-time holographic recording material: dichromated poly(vinyl alcohol). J. Phys. Chem. 1993, 97, 7228-7233.
(52) Westheimer, F. H. The Mechanisms of Chromic Acid Oxidations. Chem. Rev. 1949, 45, 419-451.

(53) Signorella, S.; Daier, V.; García, S.; Cargnello, R.; González, J. C.; Rizzotto, M.; Sala, L. F. The relative ability of aldoses and deoxyaldoses to reduce $\mathrm{Cr}(\mathrm{VI})$ and $\mathrm{Cr}(\mathrm{V})$. A comparative kinetic and mechanistic study. Carbohydr. Res. 1999, 316, 14-25.

(54) Mangiameli, M. F.; González, J. C.; Bellú, S.; Bertoni, F.; Sala, L. F. Redox and complexation chemistry of the $\mathrm{Cr}(\mathrm{VI}) / \mathrm{Cr}(\mathrm{V})-\mathrm{d}-$ glucaric acid system. Dalton Trans. 2014, 43, 9242-9254.

(55) Rahman, M.; Rocek, J. Mechanism of chromic acid oxidation of isopropyl alcohol. Evidence for oxidation by chromium(IV). J. Am. Chem. Soc. 1971, 93, 5462-5464.

(56) Hasan, F.; Rocek, J. Three-electron oxidations. IX. Chromic acid oxidation of glycolic acid. J. Am. Chem. Soc. 1975, 97, 14441450.

(57) Hasan, F.; Roček, J. The chromic acid oxidation of oxalic acid. Tetrahedron 1974, 30, 21-24.

(58) Wolbers, R. Cleaning Painted Surfaces: Aqueous Methods, Archetype Publications Ltd: London, 2000.

(59) Nieboer, E.; Jusys, A. Biological Chemistry of Chromium. In Chromium in the Natural and Human Environments; Nriagu, J. O., Nieboer, E., Eds.; John Wiley and Sons, Inc.: Hoboken, 1988, pp 2179.

(60) Jiang, B.; Wang, X.; Hu, P.; Wu, M.; Zheng, J.; Wu, W. Dual enhancement-inhibition roles of polycarboxylates in $\mathrm{Cr}(\mathrm{VI})$ reduction and organic pollutant oxidation in electrical plasma system. Chemosphere 2016, 144, 1611-1617.

(61) Signorella, S.; Lafarga, R.; Daier, V.; Sala, L. F. The reduction of $\mathrm{Cr}(\mathrm{VI})$ to $\mathrm{Cr}(\mathrm{III})$ by the $\alpha$ and $\beta$ anomers of d-glucose in dimethyl sulfoxide. A comparative kinetic and mechanistic study. Carbohydr. Res. 2000, 324, 127-135.

(62) Roldán, V. P.; Daier, V. A.; Goodman, B.; Santoro, M. I.; González, J. C.; Calisto, N.; Signorella, S. R.; Sala, L. F. Kinetics and Mechanism of the Reduction of Chromium(VI) and Chromium(V) by D-Glucitol and D-Mannitol. Helv. Chim. Acta 2000, 83, 32113228.

(63) Mallégol, J.; Gardette, J. L.; Lemaire, J. Long-term behavior of oil-based varnishes and paints. Fate of hydroperoxides in drying oils. $J$. Am. Oil Chem. Soc. 2000, 77, 249-255.

(64) Colombini, M. P.; Modugno, F.; Fuoco, R.; Tognazzi, A. A GCMS study on the deterioration of lipidic paint binders. Microchem. J. 2002, 73, 175-185.

(65) Lazzari, M.; Scalarone, D.; Malucelli, G.; Chiantore, O. Durability of acrylic films from commercial aqueous dispersion: Glass transition temperature and tensile behavior as indexes of photooxidative degradation. Prog. Org. Coat. 2011, 70, 116-121.

(66) Krumpolc, M.; DeBoer, B. G.; Rocek, J. A stable chromium(V) compound. Synthesis, properties, and crystal structure of potassium bis(2-hydroxy-2-methylbutyrato)oxochromate(V) monohydrate. J. Am. Chem. Soc. 1978, 100, 145-153.

(67) Chiantore, O.; Trossarelli, L.; Lazzari, M. Photooxidative degradation of acrylic and methacrylic polymers. Polymer 2000, 41, $1657-1668$

(68) Sangaj, N. S.; Malshe, V. C. Permeability of polymers in protective organic coatings. Prog. Org. Coat. 2004, 50, 28-39.

(69) Eppensteiner, F. W.; Jenkins, M. R. Chromate conversion coatings. Met. Finish. 2002, 100, 479-491.

(70) Berrie, B.; Casadio, F.; Dahm, K.; Strumfels, Y.; Tedeschi, M.; Walsh, J. A. Vibrant Surface: Investigating Color, Texture and Transparency in Winslow Homer's Watercolors. In Science and Art: The Painted Surface; Sgamellotti, A., Brunetti, B. G., Miliani, C., Eds.; Royal Society of Chemistry: London, 2014; pp 404-428.

(71) Townsend, C. A. Delegation Debate. Pap. Conserv. 1998, 98, $21-28$.

(72) Singer, B.; Aslaksby, T. E.; Topalova-Casadiego, B.; Tveit, E. S. Investigation of Materials Used by Edvard Munch. Stud. Conserv. 2010, 55, 274-292.

(73) Cotte, M.; Fabris, T.; Langlois, J.; Bellot-Gurlet, L.; Ploye, F.; Coural, N.; Boust, C.; Gandolfo, J.-P.; Galifot, T.; Susini, J. 
Rediscovering Ducos du Hauron's Color Photography through a Review of His Three-Color Printing Processes and Synchrotron Microanalysis of His Prints. Angew. Chem., Int. Ed. 2018, 57, 73647368.

(74) Zanella, L.; Casadio, F.; Gray, K. A.; Warta, R.; Ma, Q.; Gaillard, J. F. The darkening of zinc yellow: XANES speciation of chromium in artist's paints after light and chemical exposures. J. Anal. At. Spectrom. 2011, 26, 1090-1097.

(75) Casadio, F.; Xie, S.; Rukes, S. C.; Myers, B.; Gray, K. A.; Warta, R.; Fiedler, I. Electron energy loss spectroscopy elucidates the elusive darkening of zinc potassium chromate in Georges Seurat's A Sunday on La Grande Jatte-1884. Anal. Bioanal. Chem. 2011, 399, 29092920.

(76) Christiansen, M. B.; Sørensen, M. A.; Sanyova, J.; Bendix, J.; Simonsen, K. P. Characterisation of the rare cadmium chromate pigment in a 19th century tube colour by Raman, FTIR, X-ray and EPR. Spectrochim. Acta, Part A 2017, 175, 208-214.

(77) Otero, V.; Campos, M. F.; Pinto, J. V.; Vilarigues, M.; Carlyle, L.; Melo, M. Heritage Sci. 2017, 5, 46. 